\title{
REVIEW
}

\section{Multifaceted roles of GSK-3 and Wnt/ $\beta$-catenin in hematopoiesis and leukemogenesis: opportunities for therapeutic intervention}

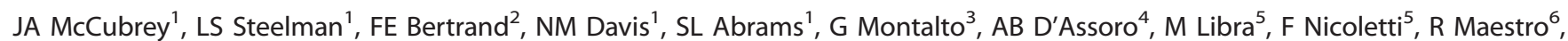 \\ J Basecke ${ }^{7,8}$, L Cocco $^{9}$, M Cervello $^{10}$ and AM Martelli, ${ }^{9,11}$
}

\begin{abstract}
Glycogen synthase kinase-3 (GSK-3) is well documented to participate in a complex array of critical cellular processes. It was initially identified in rat skeletal muscle as a serine/threonine kinase that phosphorylated and inactivated glycogen synthase. This versatile protein is involved in numerous signaling pathways that influence metabolism, embryogenesis, differentiation, migration, cell cycle progression and survival. Recently, GSK-3 has been implicated in leukemia stem cell pathophysiology and may be an appropriate target for its eradication. In this review, we will discuss the roles that GSK-3 plays in hematopoiesis and leukemogenesis as how this pivotal kinase can interact with multiple signaling pathways such as: Wnt/ $\beta$-catenin, phosphoinositide 3-kinase (PI3K)/phosphatase and tensin homolog (PTEN)/Akt/mammalian target of rapamycin (mTOR), Ras/Raf/MEK/extracellular signal-regulated kinase (ERK), Notch and others. Moreover, we will discuss how targeting GSK-3 and these other pathways can improve leukemia therapy and may overcome therapeutic resistance. In summary, GSK-3 is a crucial regulatory kinase interacting with multiple pathways to control various physiological processes, as well as leukemia stem cells, leukemia progression and therapeutic resistance. GSK-3 and Wnt are clearly intriguing therapeutic targets.
\end{abstract}

Leukemia (2014) 28, 15-33; doi:10.1038/leu.2013.184

Keywords: GSK-3; leukemia stem cells; Wnt/ $\beta$-catenin; Akt; targeted therapy; therapy resistance

\section{GSK-3 IS IMPORTANT IN DIVERSE DISEASES}

Glycogen synthase kinase-3 (GSK-3) is a serine (S)/threonine(T) kinase. It was initially identified in rat skeletal muscle as a kinase that phosphorylated and inactivated glycogen synthase (GS). GS is the last enzyme in glycogen biosynthesis. ${ }^{1-2}$ Obviously, one of the initially identified roles of GSK-3 was in metabolism. Aberrant activity of GSK-3 has also been implicated in the pathologies of many diseases and disorders such as metabolic disorders (diabetes, atherosclerosis, heart disease), neurological disorders (Parkinson's, Alzheimer's, amyotrophic lateral sclerosis, schizophrenia, bipolar disorder, mood disorders), cancer and aging (cellular senescence, cancer stem cells, control of stem cell pluripotency and differentiation), immune disorders and other maladies among others. ${ }^{3-7}$ GSK-3 may be a key therapeutic target for leukemia and other diseases because of the diversity of pathways with which it interacts (Wnt/ $\beta$-catenin, PI3K/PTEN/Akt/ mTORC1, Ras/Raf/MEK/ERK, Hedgehog (Hh), Notch and others). ${ }^{8-22}$

Aberrant GSK-3 expression has also been observed in cancers that are resistant to radiotherapy, chemotherapy and targeted therapy..$^{5}$ Targeting GSK-3 has been shown to increase the sensitivity of resistant cells to certain drugs and other small-molecule inhibitors. ${ }^{6,7}$

\section{GSK-3 FAMILY OF KINASES}

GSK-3 gene family consists of two highly conserved kinases: GSK- $3 \alpha$ and GSK-3 $\beta$. GSK3A encodes a protein of $51 \mathrm{kDa}$, whereas GSKB encodes a protein of $47 \mathrm{kDa} .{ }^{23} \mathrm{GSK}-3 \alpha$ has a glycine-rich extension at its amino terminus. GSK- $3 \alpha$ and GSK-3 $\beta$ share $98 \%$ sequence identity in their kinase domains but $36 \%$ identity in their carboxyl terminus. $^{24}$ Both GSK-3 $\alpha$ and GSK-3 $\beta$ are active in nonstimulated cells. GSK-3s have preferences for primed substrates; this means they prefer substrates that have already been phosphorylated by other kinases.

\section{REGULATION OF GSK-3 ACTIVITY BY PHOSPHORYLATION}

GSK- $3 \alpha$ and GSK-3 $\beta$ are ubiquitously expressed and highly conserved. GSK-3 $\beta$ phosphorylates more than 40 proteins including over 12 transcription factors. ${ }^{25}$ They are both inactivated by diverse stimuli and signaling pathways. GSK-3 $\alpha$ is inactivated by phosphorylation at S21, whereas GSK-3 $\beta$ is inactivated by phosphorylation at S9. These modifications inhibit the GSK-3s by inducing a pseudosubstrate conformation in the GSKs, which is the interaction of S21 and S9 residues with the substrate docking motif of GSK-3 $\alpha$ and GSK-3 $\beta$, respectively. ${ }^{24}$

\footnotetext{
${ }^{1}$ Department of Microbiology and Immunology, Brody School of Medicine at East Carolina University, Greenville, NC, USA; ${ }^{2}$ Department of Oncology, Brody School of Medicine at East Carolina University, Greenville, NC, USA; ${ }^{3}$ Biomedical Department of Internal Medicine and Specialties, University of Palermo, Palermo, Italy; ${ }^{4}$ Department of Biochemistry and Molecular Biology, Mayo Clinic College of Medicine, Rochester, MN, USA; ${ }^{5}$ Department of Bio-Medical Sciences, University of Catania, Catania, Italy; ${ }^{6}$ Experimental Oncology 1 , CRO IRCCS, National Cancer Institute, Aviano, Italy; ${ }^{7}$ Department of Medicine, University of Göttingen, Göttingen, Germany; ${ }^{8}$ Sanct-Josef-Hospital Cloppenburg, Department of Hematology and Oncology, Cloppenburg, Germany; ${ }^{9}$ Dipartimento di Scienze Biomediche e Neuromotorie, Università di Bologna, Bologna, Italy; ${ }^{10}$ Consiglio Nazionale delle Ricerche, Istituto di Biomedicina e Immunologia Molecolare 'Alberto Monroy', Palermo, Italy and ${ }^{11}$ Institute of Molecular Genetics, National Research Council-IOR, Bologna, Italy. Correspondence: Dr JA McCubrey, Department of Microbiology and Immunology, Brody School of Medicine at East Carolina University, Brody Building 5N98C, Greenville, NC 27858 USA.

E-mail: mccubreyj@ecu.edu

Received 7 May 2013; revised 8 June 2013; accepted 11 June 2013; accepted article preview online 19 June 2013; advance online publication, 12 July 2013
} 
S9 phosphorylation of GSK-3 $\beta$ results in its inactivation by proteosomal degradation and has been associated with many pathological conditions. Diverse kinases can phosphorylate GSK-3 $\beta$ at 59 including protein kinase A, protein kinase B (also known as Akt), p90 ribosomal $S 6$ kinase (p90 Rsk) and p70 ribosomal S6 kinase (p70S6K). ${ }^{23-26}$

Insulin signaling causes inactivation of GSK-3 $\beta$ (S9) and GSK-3 $\alpha$ (S21) by activated Akt. ${ }^{23-26}$ Epidermal growth factor, plateletderived growth factor and certain other growth factors also cause inactivation of GSK-3 $\beta$ (S9) and GSK-3 $\alpha$ (S21) by activated Raf/MEK/ERK/p90 Rsk1 signaling. Multiple signaling pathways may mediate the phosphorylation and inactivation of GSK-3 $\beta$ and GSK-3 $\alpha$ by phosphorylation at S9 and S21, respectively. ${ }^{23-26}$

GSK-3 $\beta$ activity is also regulated by phosphorylation at tyrosine (Y) 216. Some scientists have suggested that this is due to autophosphorylation. ${ }^{27}$ The corresponding residue in GSK-3 $\alpha$ is Y279. Phosphorylation of GSK-3 $\beta$ at Y216 is believed to be constitutive in resting cells. ${ }^{27}$ The biochemical roles of phosphorylation of GSK-3 $\beta$ at Y216 are not clear. Apoptotic stimuli can increase GSK-3 $\beta$ phosphorylation at Y216, suggesting roles for GSK-3 $\beta$ in apoptosis. ${ }^{28,29}$ Some studies have suggested that proline-rich tyrosine kinase 2 (PYK2) may phosphorylate GSK-3s at Y216 and Y270. ${ }^{30}$ This may serve to activate GSK-3 in certain biochemical situations. PYK2 has been shown to control lysophosphatidic acid-induced activation of GSK-3 that leads to the phosphorylation of microtubule-associated proteins. The Fyn tyrosine kinase is another kinase that may phosphorylate GSKs. ${ }^{31}$ The p38 mitogen-activated protein kinase can phosphorylate GSK-3 $\beta$ at S389/T390. ${ }^{32}$ Extracellular signal-regulated kinase (ERK) may phosphorylate GSK-3 $\beta$ at T43, promoting a conformational change resulting in altering its activity. ${ }^{25}$ There may also be protein phosphatases (for example, PP2A, PP1) that play important roles in the regulation of GSK-3 activity by removing the phosphate on S9. ${ }^{33}$ In addition, GSK-3 may have protein phosphatases as substrates (for example, PP1G). ${ }^{25}$

\section{TARGETS AND FUNCTIONS OF GSK-3}

GSK-3 can alter the activity of p70S6K and cellular proliferation. ${ }^{34}$ The mammalian GSK-3 homolog Mck1 can inhibit the activity of the major mitotic cyclin-Cdk complex $\mathrm{Clb2}-\mathrm{Cdk} 1$ and affect cellular division. ${ }^{35}$

Inhibition of GSK-3 resulted in activation of $\mathrm{p} 27^{\mathrm{Kip}-1}$ and induced cell cycle arrest at the $\mathrm{G}_{1}$ phase. ${ }^{36} \mathrm{GSK}-3$ phosphorylated p21 ${ }^{\mathrm{Cip} 1}$ at T57 that led to its proteasomal degradation. ${ }^{37}$ Inactive GSK-3 prevented phosphorylation of cyclin D1 at T286 and cyclin E at S380. This prevented their nuclear export and degradation. ${ }^{38,39}$

GSK-3 has many effects on cell growth, some of which are indirect. As GSK-3 can regulate the activity of transcription factors, it has profound regulatory roles on cellular proliferation. ${ }^{40}$ Growth arrest and DNA damage-inducible 45 (GADD45) and GADD153 encode tumor suppressors and checkpoint inhibitors. GSK-3 $\beta$ can regulate the activity of p53 that can, in turn, control GADD45 transcription. GADD45 can be induced by DNA damage and its expression is controlled by $\mathrm{p} 53$. When GADD45 is induced, the cell cycle is arrested. GSK-3 $\beta$ can also regulate the activity of c-Myc that, in turn, can modulate the expression of the GADD45 and GADD153 genes. c-Myc can also control the expression of cell division cycle 25A (CDC25), which is also an important cell cycle regulator. ${ }^{40}$ GSK-3 also controls the activity of the transcription factors such as (nuclear factor- $\kappa \mathrm{B}(\mathrm{NF}-\kappa \mathrm{B}){ }^{40}$ The focal adhesion kinase is regulated by NF- $\kappa B$ and GSK-3. ${ }^{41}$

GSK-3 $\beta$ expression can also play roles in the regulation of apoptotic and anti-apoptotic family members. GSK-3 $\beta$ can inhibit B-cell lymphoma 2 (BCl-2) expression by phosphorylation of CREB. $^{42}$ GSK-3 can also regulate the myeloid cell leukemia sequence 1 (Mcl-1) anti-apoptotic factor, ${ }_{13}^{43}$ although some recent studies suggest that GSK-3 activity may not be necessary for Mcl-1 degradation. ${ }^{44}$ In addition, some studies have shown that GSK-3 stabilizes the expression of certain anti-apoptotic $\mathrm{Bcl}-2$ family members in leukemia cells. ${ }^{45}$

GSK-3 $\beta$ also has effects on the expression of the myeloblastosis transcription factor (c-Myb) that is important in the regulation of $B C L 2$ transcription. Inhibition of GSK-3 $\beta$ repressed the expression of c-Myb that, in conjunction with the lymphoid enhancer-binding factor 1 (LEF-1) transcription factor, binds the promoter regions of the BCL2 and BIRC5 (survivin) genes to prevent apoptosis of leukemia cells. ${ }^{46}$

\section{BIOCHEMICAL AND PHYSIOLOGICAL DIFFERENCES BETWEEN GSK-3 $\alpha$ AND GSK-3 $\beta$}

Although GSK-3 $\alpha$ and GSK-3 $\beta$ are structurally similar, they are not functionally identical. For example, GSK-3 $\alpha$ cannot completely compensate for GSK-3 $\beta$ as GSK-3 $\beta$ knockout (deletion of exon 2) mice are embryonically lethal and die around embryonic day 16 because of liver degeneration caused by hepatocyte apoptosis. ${ }^{47}$ These studies also demonstrated that GSK-3 $\beta$ was essential for the activation of NF- $\kappa B$ after tumor necrosis factor- $\alpha$ treatment in hepatocytes. In contrast to GSK-3 $\beta$ knockout mice, GSK-3 $\alpha$ knockout mice animals were viable but displayed enhanced glucose and insulin sensitivity and reduced fat mass. GSK- $3 \alpha$ knockout mice elicited metabolic and neuronal developmental abnormalities. ${ }^{48,49}$ It has also been demonstrated that GSK-3 $\alpha$ and GSK-3 $\beta$ have different substrate preferences in the brain. ${ }^{50}$ In summary, GSK-3 isoforms exhibit tissue-specific physiologically important functions that are sometimes different. Thus, there are rationales for the specific targeting of GSK-3 $\alpha$ or GSK-3 $\beta$ in certain diseases.

Most studies have focused on GSK-3 $\beta$; however, some studies have demonstrated roles for GSK-3 $\alpha$ in drug resistance and cancer stem cells. GSK-3 $\alpha$ has also been identified as a key target in other cancers including acute myeloid leukemia (AML). ${ }^{51}$

\section{INTERACTIONS BETWEEN GSK-3 AND PI3K/PTEN/AKT/MTORC1 PATHWAY}

GSK-3 is a critical enzyme that is often associated with the phosphoinositide 3-kinase (PI3K)/phosphatase and tensin homolog (PTEN)/Akt/mammalian target of rapamycin complex 1 (mTORC1) and Wnt/ $\beta$-catenin pathways that are often deregulated in leukemia and myeloma. ${ }^{52-68}$ GSK-3 has complex interactions with these pathways. Some of the interactions of GSK-3 and the PI3K/PTEN/Akt/mTORC1 and Ras/Raf/MEK/ERK pathways are presented in Figure 1. GSK-3 $\beta$ can be negatively regulated through phosphorylation on $\mathrm{S} 9$ by active Akt. When GSK-3 $\beta$ is phosphorylated by Akt, GSK-3 $\beta$ is inactive.

\section{TSC1/TSC2 REGULATION OF MTORC1}

Akt-mediated regulation of mTORC1 activity is a complex, multistep phenomenon. Akt inhibits tuberous sclerosis complex 2 (TSC2; tuberin) function through direct phosphorylation. ${ }^{64}$ TSC2 is a GTPase-activating protein (GAP) that functions in association with tuberous sclerosis complex 1 (TSC1; hamartin) to inactivate the small G-protein Rheb (Ras homolog enriched in brain). ${ }^{64}$ TSC2 phosphorylation by Akt represses GAP activity of the TSC1/TSC2 complex, allowing Rheb to accumulate in a guanosine5 '-triphosphate (GTP)-bound state. Rheb-GTP then activates, through a mechanism not yet fully elucidated, the protein kinase activity of mTOR present in the mTORC1 complex. Clearly, regulation of these complexes play critical important roles in cell proliferation and leukemia. These are sites of intervention in many antileukemia and anticancer therapies. ${ }^{52-64}$

TSC1/TSC2 can regulate mTORC1 activity and GSK-3 can play a key role in this regulatory circuit. The TSC1/TSC2 complex can 


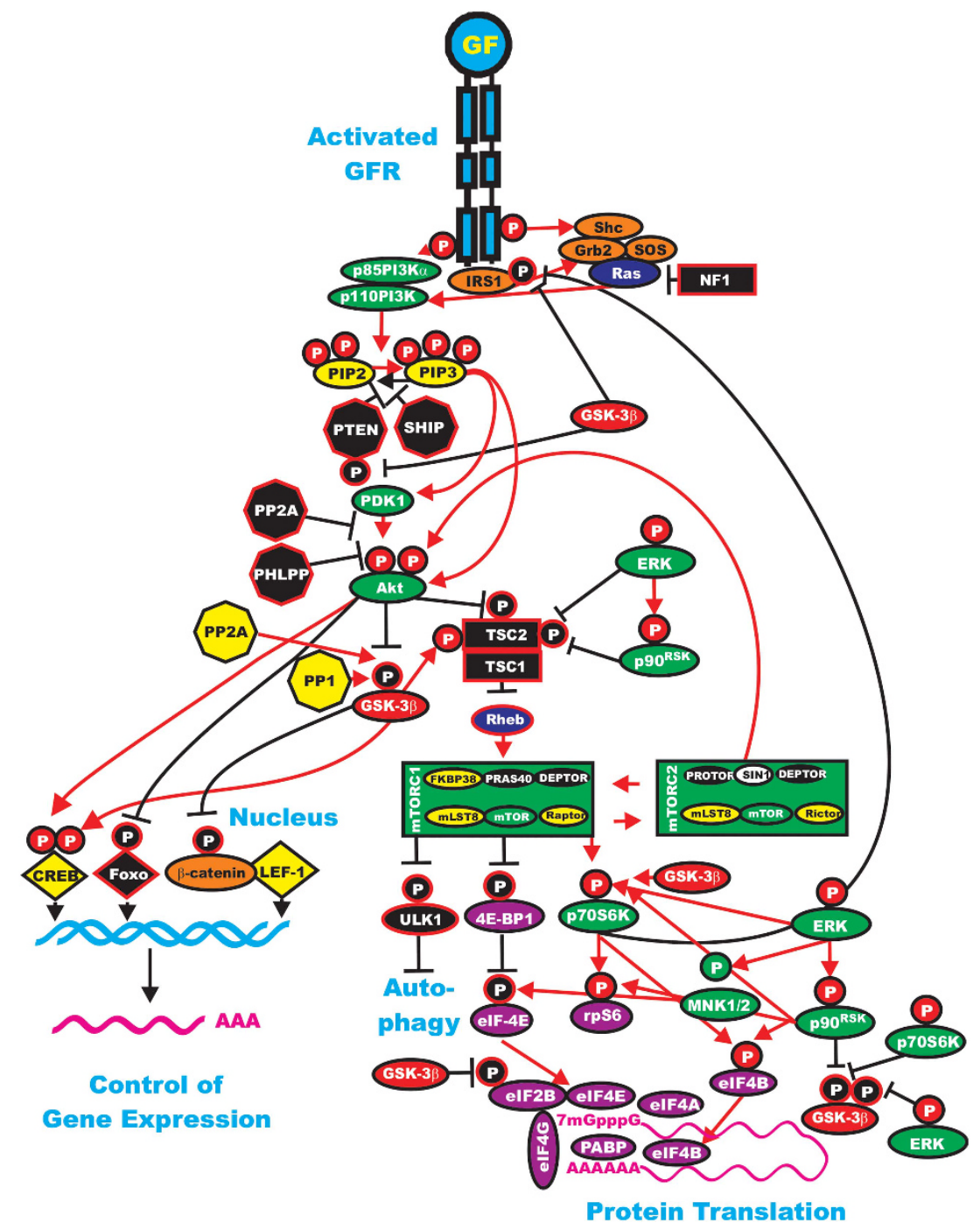

Figure 1. Interactions of the Ras/PI3K/PTEN/Akt/mTOR and Ras/Raf/MEK/ERK pathways with GSK-3. Some of the regulatory interactions between GSK-3 and Ras/PI3K/PTEN/Akt/mTOR and Ras/Raf/MEK/ERK pathways are indicated. An activated growth factor receptor is indicated in blue. Ras and Rheb are indicated in dark blue ovals. IRS1 is indicated in an orange oval. Kinases are indicated in green ovals with the exception of GSK-3 $\beta$, which is indicated in a red oval. The p85 regulatory subunit of PI3K is indicated in a green oval. The phosphatases that inhibit steps in this pathway are indicated in black octagons. The phosphatases PP2A and PP1 that may activate GSK-3 are indicated in yellow octagons. NF1, TSC1 and TSC2 are indicated in black squares. PIP2 and PIP3 are indicated in yellow ovals. Phosphatases are indicated in black octagons. mTOR interacting proteins that positively regulate mTOR activity are indicated in yellow ovals. mTOR interacting proteins that negatively regulate mTOR activity are indicated in black ovals. Transcription factors activated by either ERK or Akt phosphorylation are indicated in yellow diamonds. The FOXO transcription factor that is inactivated by Akt phosphorylation is indicated by a black diamond. $\beta$-Catenin is indicated in an orange oval. mRNA initiation factors and proteins associated with the ribosome are indicated in magenta ovals. mTORC1 phosphorylates the ULK1 (unc-51-like kinase 1) that results in the suppression of autophagy. ULK1 is indicated in a black oval. Proteins involved in the regulation of translation are indicated in purple ovals. Red arrows indicate activating events in pathways. Black arrows indicate inactivating events in pathways. Activating phosphorylation events are depicted in red circles with Ps with a black outlined circle. Inactivating phosphorylation events are depicted in black circles with Ps with a red outlined circle. This figure is provided to give the reader an idea of the complex interactions of GSK-3 with various signaling molecules in the Ras/PI3K/PTEN/Akt/mTOR and Ras/Raf/MEK/ERK pathways that are key in regulating cellular proliferation survival and often become dysregulated in cancer.

negatively regulate proliferation through mTORC1 inhibition and GSK-3 $\beta$ activation. GSK-3 can also interact with TSC1/TSC2 by phosphorylating TSC2 and activating it. $^{64}$

GSK-3 can phosphorylate p70S6K. ${ }^{34}$ This is another point where GSK-3 interacts with the PI3K/Akt/mTOR pathway. GSK-3 can phosphorylate $\mathrm{S} 371$ on p70S6K and regulate its activity. mTORC1 cooperates with GSK-3 to regulate p70S6K activity and cell proliferation. $^{34}$ GSK-3 can phosphorylate TSC2 that results in inhibition of mTORC1 and subsequent phosphorylation of p70S6K at T389. ${ }^{66}$

\section{OVERVIEW OF WNT/ $\beta$-CATENIN SIGNALING AND CRITICAL INVOLVEMENT OF GSK-3}

There are basically two Wnt signaling pathways: one is referred to as canonical Wht signaling, which is $\beta$-catenin dependent, whereas the other signaling pathway is referred to as noncanonical Wnt signaling, which is $\beta$-catenin independent. $\beta$-Catenin can play various roles in cell physiology. Different pools of $\beta$-catenin have been proposed to be present at different locations in the cell. One pool of $\beta$-catenin is associated with cadherins at the cell-cell junctions. Another pool of $\beta$-catenin is 'free' and 
present in the cytosol and nucleus where it plays important roles in regulating gene expression. Normally, this pool of 'free' $\beta$-catenin is maintained at a low level by rapid turnover. GSK-3 is important in regulating the turnover of $\beta$-catenin. An overview of the Wnt/ $\beta$-catenin pathway is presented in Figure 2.

The Wnt gene family consists of $\sim 19$ genes in mammals. Wnt genes are present in multicellular animals but not in single-cell organisms, suggesting a key role for the Wnt genes in the evolution of multicellular organisms. ${ }^{67,68}$ Signaling induced by heterodimeric Wnt receptors results in a ligand-induced conformation change of the receptors, resulting in the phosphorylation of target proteins. Wnt binds a member of the Frizzled (Fz) family members $(N=10)$, the membrane-bound receptors that are $\mathrm{G}$ protein-coupled receptors. A co-receptor for
Wnt is the transmembrane protein called low-density lipoprotein receptor-related proteins 5/6 (LRP5 or LRP6). In addition, there are other receptor tyrosine kinases such as the receptor-tyrosinekinase-like orphan receptor 1 (ROR1) and ROR2 as well as the receptor tyrosine kinase-like proteins that can interact with Wnt. $^{52,68}$

\section{BIOCHEMICAL REGULATION OF $\boldsymbol{\beta}$-CATENIN BY GSK-3}

In unstimulated cells, CK1 phosphorylates $\beta$-catenin at S45 that primes $\beta$-catenin for subsequent phosphorylation by GSK-3 at S41, S37 and S33. $4,67,68$ Thus, $\beta$-catenin is targeted for ubiquitination and proteasomal degradation. ${ }^{24}$ An enlarged view
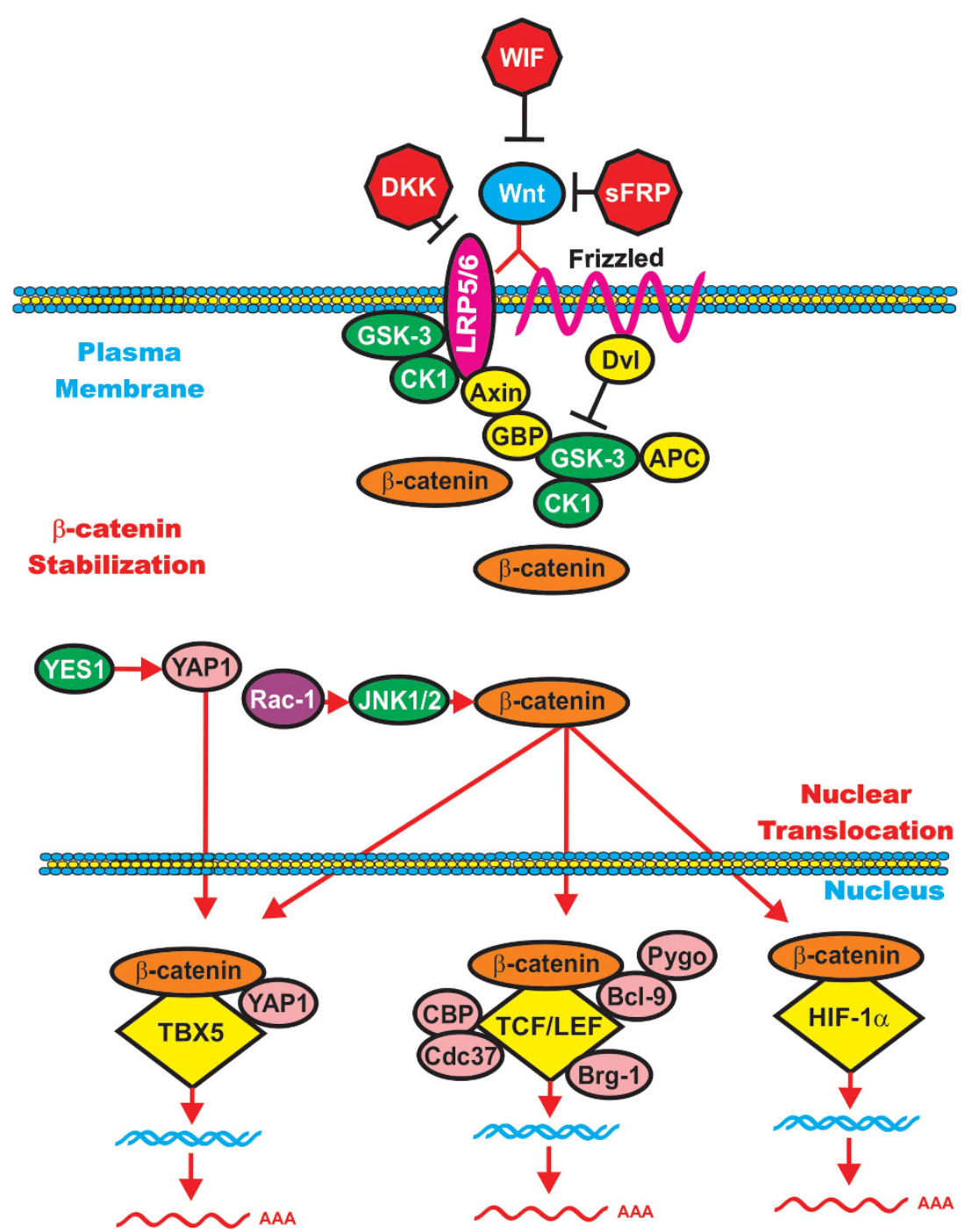

BCL2L1, Survivin and other genes

Cyclin D1, c-Myc, PPAR $\delta, \quad$ HIF-1 $\alpha$ dependent DKK1, Axin2, c-Jun, VEGF, gene transcription YAP1 and other genes

Figure 2. Overview of Wnt/ $\beta$-catenin induced gene expression. In the presence of Wnt, $\beta$-catenin is stabilized and can induce gene transcription. Wht binds its coreceptors Fz and LRP5/LRP6. The Fz transmembrane receptor is indicated by a squiggly line to indicate its spanning the membrane seven times. The LRP5 and LRP6 transmembrane receptors are indicated by a red oval. Various molecules that interact with the receptors and GSK-3 and CK1 are indicated in yellow ovals. Various Wnt inhibitors such as WIF, DKK and sFRP are presented as red octagons. When Wnt is present, $\beta$-catenin is stabilized and able to induce gene expression by complexing with various transcription factors including TCF/LEF, TBX5 and HIF- $1 \alpha$ that are indicated by yellow diamonds. Various proteins that interact with the transcription factor complexes are indicated in pink circles. Kinases that can regulate these molecules are indicated by green ovals. The Rac- 1 exchange factor is indicated in a purple circle. This figure is presented to provide the reader an idea of how activation of Wnt/ $\beta$-catenin can result in regulation of gene expression. 
of the Wnt/ $\beta$-catenin and $\beta$-catenin destruction complex is presented in Figure 3.

If the Wnt ligand is present, it binds its receptor $F z$, which signals through Dvl to suppress $\beta$-catenin phosphorylation, and $\beta$-catenin is able to complex with LEF/T-cell factor (TCF) and induce the transcription of genes. When mutated, $\beta$-catenin acts as an oncogene, as in some cases it cannot be phosphorylated by GSK-3 and CKI. Other regulatory proteins are also involved. Some of them are oncogenes/tumor-suppressor genes. The GSK-3-binding protein (GBP, also known as FRAT (frequently

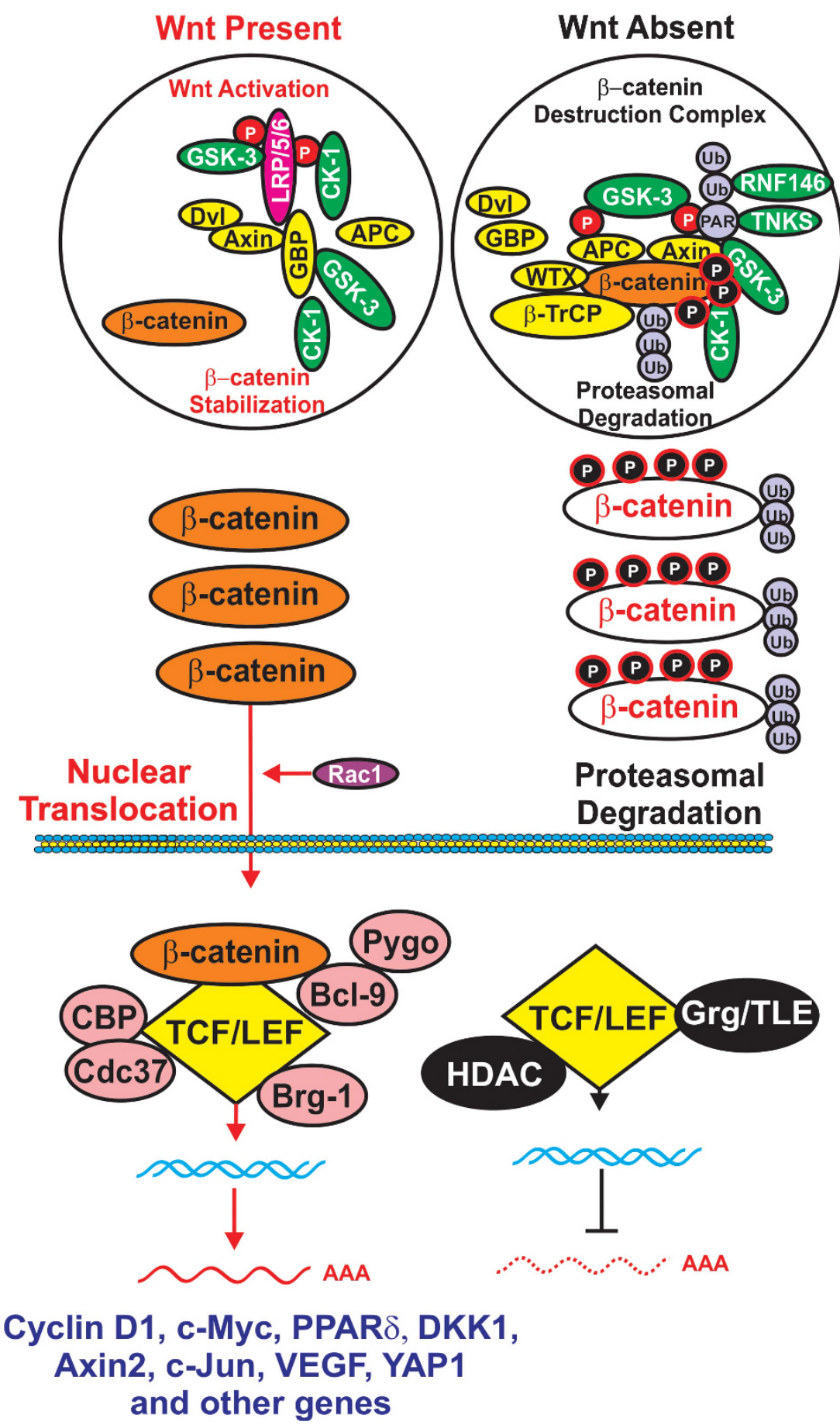

Figure 3. Comparison of Wnt activation of $\beta$-catenin signaling vs formation of $\beta$-catenin destruction complex. (Left panel) In the presence of Wnt, $\beta$-catenin is stabilized and can induce gene transcription. Various proteins that interact with the transcription factor complexes are indicated in pink circles. The Rac-1 exchange factor is indicated in a purple circle. When Wnt is absent, $\beta$-catenin is targeted for proteasomal degradation. GMP, indicated in a yellow oval, is displaced from GSK-3 and GSK-3 is able to phosphorylate $\beta$-catenin that results in its ubiquitination by the $\beta$-TrCP complex, indicated in a yellow oval. Ubiquitination is indicated by Ub in purple circles. Axin is also poly-ADPribosylated TNKS that is linked by PAR indicated by a purple circle that subsequently leads to its proteasomal degradation. TCF/LEF interacts with various proteins including the transcriptional regulators histone deacetylases (HDACs) and Grg/TLE, indicated in black ovals, that prevent it from inducing gene transcription. This figure is presented to provide the reader an idea of how $\beta$-catenin turnover can be regulated by GSK-3 and CK1 phosphorylation. 
rearranged in advanced T cell)) may regulate the binding of GSK-3 to Axin. Diversin (Div) is an ankyrin-rich protein and can interact with both Dvl and Axin to facilitate Wnt signaling. The $\beta$-catenin destruction complex consists of GSK-3, $\beta$-catenin, Axin/conductin and adenomatous polyposis coli (APC). APC is a tumor-suppressor gene. APC is an essential component of the $\beta$-catenin complex that controls cytoplasmic $\beta$-catenin levels. Mutations at APC result in elevated levels of $\beta$-catenin and lead to the expression of $W n t / \beta$-catenin-responsive genes. The Axin and related conductin (Axil) proteins contain multiple protein-protein interaction domains and together with APC form key components of the $\beta$-catenin destruction complex. GSK-3 phosphorylates both Axin and APC. GSK-3 phosphorylation of Axin increases it stability as well as its binding to $\beta$-catenin. ${ }^{69} \mathrm{CKI}$ acts as a priming kinase by phosphorylating Axin, Dvl and APC. GSK-3 then phosphorylates these proteins. The Div protein recruits $C K I$ to the $\beta$-catenin destruction complex. ${ }^{70}$

GBP plays key regulatory roles in the interactions that GSK-3 has with other proteins. The binding sites for Axin and GBP on GSK-3 overlap. If GSK-3 is bound to GBP, GSK-3 cannot bind Axin and GSK-3 does not phosphorylate $\beta$-catenin. ${ }^{71}$ GBP also regulates the nuclear export of GSK-3 $3^{72}$ and may control the accessibility of nuclear and cytoplasmic substrates to GSK-3.

Dvl binds the cytoplasmic portion of Fz. Wnt/Fz then becomes associated with LRP5 or LRP6, which are co-receptors for Wnt. Casein kinase $1 \delta(C K I \delta)$ phosphorylates LRP6 on T1479. GSK-3 $\beta$ can then play a positive role in Wnt signaling by phosphorylating LRP6 on S1490. These phosphorylation events are necessary for Axin to bind to the complex and $\beta$-catenin stabilization. The stabilized $\beta$-catenin can then enter the nucleus and have effects on gene transcription. ${ }^{73} \mathrm{~A}$ diagram of the positive effects that $\mathrm{CKI}$ and GSK-3 exert on Wnt/ $\beta$-catenin signaling is present in Figure 4. This figure also illuminates why GSK-3 inhibitors may be effective in targeting certain leukemias.

Axin binds to the cytoplasmic portion of LRP6. This complex may then recruit $\beta$-catenin from the $\beta$-catenin destruction complex and inhibit the ability of GSK-3 to phosphorylate $\beta$-catenin (CTNNB1). When Wnt signaling is active, GSK-3-mediated phosphorylation of S33, S37 and T41 on $\beta$-catenin is suppressed. In contrast, there is no effect on $\mathrm{CK} 1 \alpha$-mediated phosphorylation of S45.

Thus, there are two roles for GSK-3 in the regulation of Wnt $/ \beta$ catenin signaling: phosphorylation of LRP5/6, which stabilizes Axin, and phosphorylation of $\beta$-catenin, which targets it for proteasomal degradation. There may be different pools of GSK-3 in cells: one linked with Axin that is resistant to phosphorylation by Akt and another pool that is regulated by Akt. ${ }^{74}$ Ectopic expression of activated Akt did not appear to activate $\beta$-catenin signaling in the cells examined as measured by changes in the levels of accumulation of cytosolic $\beta$-catenin activation of LEF1-dependent transcription. ${ }^{74}$ Wnt may induce the translocation of GSK-3 and Axin to the plasma membrane that is dependent

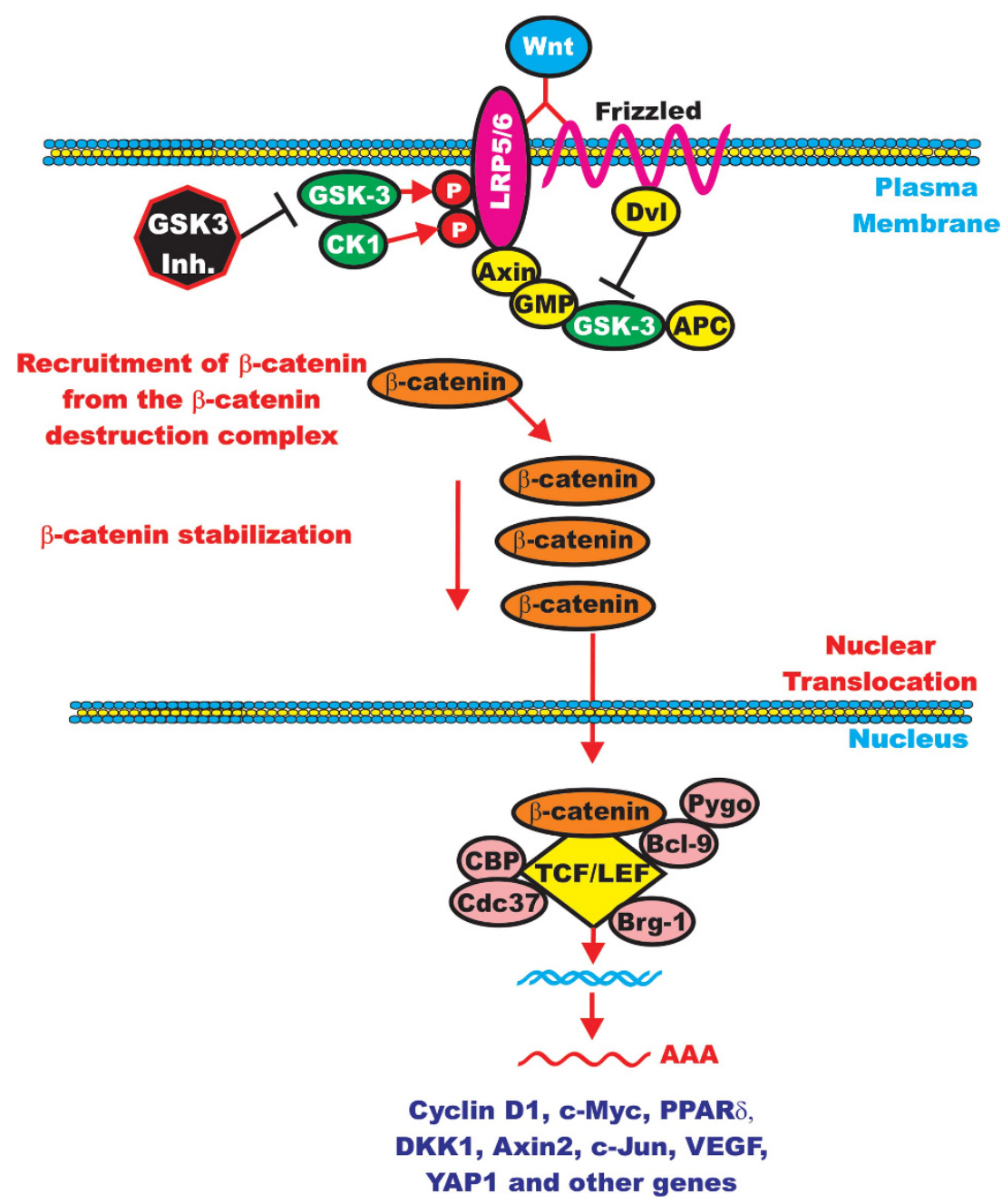

Figure 4. Positive effects of GSK-3 on Wnt/ $\beta$-catenin signaling. This figure is presented to emphasize the point that GSK-3 and CK- 1 can phosphorylate and stabilize LRP5/6 that promotes $\beta$-catenin signaling. This is a site where GSK-3 inhibitors would inhibit $\beta$-catenin-mediated gene expression. 
upon interactions with $\mathrm{Fz}$ and $\mathrm{Dvl}^{75}$ The presence of Axin is required for GSK-3 to phosphorylate LRP5/6. CKI $\gamma$ is also associated with LRP5/6 upon Wnt signaling and may also be involved in the Wnt-induced Axin recruitment. ${ }^{76}$

When Wnt signaling is turned off, $\mathrm{CKl} \alpha$ phosphorylates $\beta$-catenin on S45. Then, GSK-3 $\beta$ phosphorylates $\beta$-catenin on S33, S37 and T41. ${ }^{67,68}$ The Axin/GSK-3/CK1/APC complex normally promotes the degradation of the $\beta$-catenin via ubiquitylation by the SKP1/cullin1-F-box E3 ligase ( $\beta$-TrCP) complex in the $26 \mathrm{~S}$ proteasome. APC interacts with both GSK-3 and $\beta$-catenin. Axin functions as the scaffold of the destruction complex. APC directly binds Axin. Axin is phosphorylated by GSK-3 and CKI $\alpha$. The normal affinity of $\beta$-TrCP for $\beta$-catenin is low. Wilms tumor suppressor (WTX) is a protein that can increase the affinity of $\beta$-TrCP for $\beta$-catenin. ${ }^{77}$ WTX forms a complex with $\beta$-TrCP, $\beta$-catenin, Axin and APC. This complex promotes $\beta$-catenin ubiquitylation and subsequent proteasomal degradation.

Axin, APC and WTX are considered tumor-suppressor proteins. WTX is also present in the $\beta$-catenin destruction complex and promotes $\beta$-catenin degradation. APC has recently been shown to increase the activity of GSK-3. ${ }^{78}$ GSK-3 and CKI $\alpha$ phosphorylate a serine in the PPPSP motif found in many Wnt signaling components such as $\beta$-catenin, Axin and APC.

\section{WNT/B-CATENIN-INDUCED TRANSCRIPTIONAL EFFECTS}

Wnts induce rapid APC dissociation from Axin that leads to $\beta$-catenin stabilization. In the absence of Wnt activation, the transducin-like element (TLE, also known as Groucho, Grg) is bound to TCF and forms a transcriptional repressive complex that recruits histone deacetylases to repress Wnt target gene transcription. In the presence of binding of certain Wnts to $\mathrm{Fz}$ and LRP5 or LRP6, a signal is transmitted across the membrane and Dvl is activated. Activated Dvl then inhibits the $\beta$-catenin destruction complex. $\beta$-Catenin is not phosphorylated, it can translocate to the nucleus, replace TLE and bind transcription factor TCF/LEF and recruit numerous transcriptional co-activators and histone modifiers such as Brg-1, CBP, Cdc47, Bcl-9, Pygopus and histone acetyltransferases and induce the transcription of many genes associated with proliferation including cyclin D1, c-Myc, c-Jun, Yes-associated protein and vascular endothelial growth factor. ${ }^{67,68}$ One target of $W n t / \beta$-catenin/TCF is the Axin2 gene and is considered a general indicator of Wnt pathway activation. ${ }^{79}$ DKK1 is actually a downstream target of Wnt $/ \beta$-catenin pathway. ${ }^{80}$

\section{DIVERSE EFFECTS OF DIFFERENT WNTS}

Different Wnt family member proteins have various biological effects that may also be tissue specific. Wnt3A and Wnt7A promote the growth of certain cancers, but not others. For example, Wnt7A promotes $\beta$-catenin-dependent transcription in ovarian cancer cells. ${ }^{81}$ In contrast, it inhibits the growth of certain leukemias, potentially by a $\beta$-catenin-independent mechanism. ${ }^{82}$ The different effects of Wnt-7 on various types of cells have been postulated to result from the presence of diverse receptors expressed on the particular cell types. ${ }^{68}$ Certain Wnts will induce genes associated with differentiation and suppression of proliferation in one cell type, yet in other cell types induce the expression of genes associated with growth and survival.

\section{$\beta$-CATENIN-INDEPENDENT SIGNALING PATHWAYS}

In noncanonical Wht signaling pathways, $\beta$-catenin is not engaged; however, some of the components of the canonical Wnt signaling pathway may be involved. In some cases, Wnt5A and Wnt 1 do not stabilize $\beta$-catenin but they regulate pathways associated with cell migration and mobility. ${ }^{68}$ In some cases, Fz and Dvl are involved. In other cases, Wnt interacts with receptor tyrosine kinases located at the cell membrane such as RYK and ROR2 that transduce their signals further to Src and Jun N-terminal kinase (JNK), respectively. Wht can also interact with $\mathrm{Fz}$ and Dvl and affect CDC42 and Rac activity. Alternatively, DVL can interact with Disheveled-associated activator of morphogenesis 1 (DAAM1), Ras homolog gene family member A (RhoA) and JNK. Activation of these pathways is often associated with events at the cytoskeleton. JNK activity will also affect the expression of certain genes such as Ap-1 and nuclear factor-activated T cell (NF-AT). Wnt can also interact with Fz and Dvl and further associate with phospholipase $C$ that results in mobilization of intracellular $\mathrm{Ca} 2+$ and activates protein kinase $\mathrm{C}$ and $\mathrm{Ca} 2+$ /calmodulindependent protein kinase (CaMKII), leading to activation of NF-AT in the nucleus. There are also other pathways with which Wnts can interact, such as the planar cell polarity signaling pathway, and these pathways have been discussed in a recent comprehensive review on Wnt signaling in cancer. ${ }^{68}$ Wnt5a can inhibit proliferation and induce cellular senescence or have tumor-suppressor effects in certain cancer types as it can antagonize $\beta$-catenin-dependent transcription. ${ }^{83,84}$ Inactivation of Wnt5a expression in certain mouse models resulted in the development of B-cell lymphomas and chronic myeloid leukemias (CMLs), indicating that Wnt-5 has important tumorsuppressor activity in certain hematopoietic lineages, at least in mice. ${ }^{85}$ However, in other cancer types, Wnt-5 can enhance tumor growth.

\section{WNT RECEPTORS OVEREXPRESSED IN CANCERS}

Various $\mathrm{Fz}$ receptors have been implicated in cancer. Fz6 was determined to be overexpressed in the T-cell lymphoma breakpoint 1 (Tcl1 $+/-$, Emu-TCL1) mouse model that develops chronic lymphocytic leukemias (CLLs) spontaneously. The investigators demonstrated that during the course of leukemogenesis, expressions of Wnt16, Wnt10 $\alpha$, Fz1 and Fz6 were elevated in the transformed $\mathrm{CD} 5(+)$ B cells along with $\beta$-catenin protein levels. Creation of $\mathrm{TCl}^{+1-}, \mathrm{Fzd6}^{-/-}$double mutant mice resulted in suppression of development of the leukemia and lymphomas. In contrast, deletion of Fz9 had no effects on cancer development in this $\mathrm{TCl}^{+/-}$model. ${ }^{86}$

\section{ROLES OF WNT/B-CATENIN AND LEUKEMIA-INITIATING/STEM CELLS}

The earliest description of the involvement of the Wnt/ $\beta$-catenin pathway in cancer stem cells was probably in leukemia-initiating cells (LICs)/leukemia stem cells (LSCs). Certain LSCs have been demonstrated to have higher levels of $\beta$-catenin that was also driving their establishment and drug resistance. ${ }^{87,88}$ Other components of the $\mathrm{Wnt} / \beta$-catenin signaling pathway may be differentially expressed in certain LICS/LSCs, these include loss of functional APC, decreased expression of secreted frizzled-related protein (sFRP1), DKK1, increased expression of TCF7I2, Bcl-9, Fzd6, Wnt5A and Wnt7. Wnt/ $\beta$-catenin signaling was determined to be required for self-renewal of not only normal hematopoietic stem cells (HSC) but also LSCs.

\section{WNT SIGNALING IN STEM CELL SELF-RENEWAL}

Stem cells have the capacity to self-renew as well as produce specialized cells. The choice to self-renew or produce specialized cells may be dictated by extrinsic signaling factors that are present in the niche or in an area that functions as a signaling center. Many of these factors act within the near vicinity of the stem cells in order to tightly regulate them. Key pathways involved in regulating the niche are: Wnt, BMP, $\mathrm{Hh}$ and Notch. ${ }^{67,89,90}$ Altering the activity of the Wnt pathway has been shown to affect HSCs. 
Overexpression of Axin decreased the number of transplantable HSCs. ${ }^{91}$ Treatment of HSCs with the Wnt-3a protein increased self-renewal and long-term reconstitution in irradiated mice. ${ }^{89}$ Wnt proteins have also been shown to promote maintenance of pluripotency in murine embryonic stem cells (ESCs). ${ }^{92}$ The mechanisms by which Wnt signals maintain stemness are not fully elucidated. Clevers and Nusse ${ }^{67}$ have suggested that stem cells are intrinsically destined to differentiate and that Wnt signals could block the differentiation step by suppressing differentiationspecific genes as Wnt signals can also suppress the expression of certain genes.

\section{GSK-3 INVOLVEMENT IN HSC HOMEOSTASIS}

Normal HSCs exit quiescence under the appropriate circumstances to either maintain a balanced number of self-renewing cells or generate the required lineage-differentiated progeny cells necessary to fulfill the loss of mature blood cells. GSK-3 exerts important regulator functions on the quiescent HSC pool. GSK-3 plays key roles in HSC homeostasis. ${ }^{93}$ By using a loss of function approach, the authors demonstrated a key role of GSK-3 in controlling HSC homeostasis. Loss of functional GSK-3 activity in the bone marrow (BM) transiently expanded HSCs in a $\beta$-catenin-dependent fashion, documenting a role for $W n t / \beta$-catenin signaling in homeostasis. Loss of GSK-3 activity in the HSC led to their depletion by activation of mTORC1. Depletion of the HSCs in the GSK-3deficient BM was prevented by treatment with mTORC1 inhibitors. Thus, GSK-3 is a master switch that regulated both Wnt/ $\beta$-catenin and mTORC1 signaling that, in turn, controls HSC self-renewal and lineage commitment, respectively. The authors of this important study have suggested a potential therapeutic approach to expand HSCs in vivo using drugs already approved for treatment of other diseases (lithium to inhibit GSK-3 and rapamycin to inhibit mTORC1).

GSK-3 antagonizes mTORC1 activity by phosphorylating TSC2 that in turn inhibits Rheb and mTORC1 activity. PTEN is upstream of GSK-3. PTEN negatively regulates Akt activity. Akt negatively regulates GSK-3 activity. Interestingly, PTEN and TSC1 knockout mice have similar hematopoietic phenotypes as increases in HSCs were transiently observed that was then followed by HSC depletion and lineage commitment. ${ }^{94,95}$ There are, in addition, other tumor suppressors that were induced in PTEN-mutant mice indicating the complex interacting genetic factors between PTEN loss and mTOR activation. ${ }^{96}$ Interesting, knockdown of GSK-3 $\alpha$ and GSK-3 $\beta$ induced a similar HSC phenotype as observed in PTEN ${ }^{-/-}$ and $\mathrm{TSC}-1^{-1-}$ mice as the HSCs initially increased and then they were progressively depleted. ${ }^{97}$ These studies indicated that GSK-3 plays critical roles in the HSC homeostasis and controlling the decision between self-renewal and differentiation. These pathways have opposing functions in HSC self-renewal and differentiation. Moreover, Wnt signaling induced mTORC1 activity by inhibiting the negative effects that GSK-3 had on mTORC activity. These results suggested a division of the canonical Wnt pathway with Wnt or GSK-3 inducing opposing signal pathways, each of which can activate potentially opposing processes (HSC renewal vs differentiation). Likely, there will be other factors and molecules discovered that can shift the balance and modify HSC homeostasis.

$\mathrm{HSCs}$ reside in the BM in a reduced-nutrient and low-oxygen tension niche. Moreover, nutrient-sensing pathways interact to regulate HSC homeostasis. The mTORC1 and LKB1 pathways are key nutrient-sensing pathways and dysregulation of these pathways alters HSC homeostasis. Decreased LKB1 activity ${ }^{98}$ or increased mTORC1 activity ${ }^{96}$ will induce the proliferation of committed progenitors and decrease HSCs. These studies have indicated that low-nutrient availability is a critical component that regulates HSC homeostasis.
Subsequently, studies by the Klein group ${ }^{98}$ demonstrated that suppression of this pathway by rapamycin combined with activation of $W n t / \beta$-catenin pathway by GSK-3 inhibitors permitted ex vivo maintenance of human and mouse HSCs in the absence of exogenous cytokines. These observations further the previous studies of the authors and demonstrated that two drugs (the mTOR inhibitor rapamycin and the GSK inhibitor CHIR99021) increased the number of long-term HSCs in vivo. ${ }^{99}$ These studies document the essential regulatory roles of GSK-3 in HSC homeostasis as a suppressor of Wnt/ $\beta$-catenin self-renewal pathway and also as a suppressor of the MTORC 1 pathway that would normally promote lineage commitment and stem cell depletion. Inhibition of GSK-3 with lithium activated self-renewal, whereas suppression of $\mathrm{mTORC} 1$ with rapamycin prevented HSC depletion, allowing the generation of long-term HSCs (but not the proportion) in vivo. Thus, the approach described by Klein et al. ${ }^{98}$ may also prove useful for both hematopoietic recovery and immune reconstitution in umbilical cord blood transplantation.

The studies by Ito et al. ${ }^{100,101}$ have identified a metabolic requirement of promyelocytic leukemia (PML)-peroxisome proliferator-activated receptor- $\delta$ (PPAR $\delta$ )-fatty-acid oxidation (FAO) pathway. PPAR $\delta$ signaling and FAO is important for maintaining the equilibrium between HSC maintenance and function. The PPAR-FAO pathway is downstream of PML and can be viewed as a critical regulatory switch that is essential for HSC maintenance and control of asymmetric cell division. Both the PPAR $\delta$ pathway and FAO can be pharmacologically manipulated and therefore are relevant to stem cell and cancer therapy. Furthermore, PML can be targeted with arsenic trioxide.

Inhibition of GSK-3 allowed mouse ESCs to maintain pluripotency. ${ }^{102}$ ESCs lacking GSK- $3 \alpha$ and GSK-3 $\beta$ maintained some markers of pluripotency even when cultured under conditions that induced differentiation. ${ }^{103}$

\section{GSK-3 AND LEUKEMIA}

Over the past few years, GSK-3 has been documented to play pivotal roles in various leukemias and may therefore be a key therapeutic target. As stated previously, GSK-3 has an important role in regulating $\beta$-catenin levels. However, $\beta$-catenin is largely dispensable for the function of normal HSCs. ${ }^{104}$ In contrast, $\beta$-catenin is often important and activated in leukemia and is often associated with drug resistance and LSCs. ${ }^{87}$ Dysregulation of Wnt/ $\beta$-catenin has been observed in AML and was associated with a poor prognosis. ${ }^{105}$ Furthermore, the chemoresistance of certain AML cells was shown to be dependent on the Wnt/ $\beta$-catenin pathway and integrins. This chemoresistance required functional GSK-3 activity that mediated its effects via NF- $\kappa B$. Thus, GSK-3 is a target for certain AMLs. Note that this is an example of where GSK-3 is functioning as a tumor promoter.

Recently, it has been demonstrated by genetic and chemical genomic screens that GSK-3 $\alpha$ is a target for AML. ${ }^{51}$ The authors identified GSK-3 $\alpha$ as a target by performing two independent small-molecule library screens and a small hairpin RNA (shRNA) screen for changes in gene expression that induced a differentiation signature in two AML cell lines: HL-60 and U937. Loss of GSK-3 $\alpha$ activity induced differentiation in AML cells as measured by many parameters including morphological changes, cell surface marker expression and gene expression signatures, all being consistent with myeloid differentiation. GSK-3 $\alpha$ inhibition resulted in impaired growth and proliferation, induction of apoptosis, loss of colony-forming ability in methylcellulose in vitro and inhibition of AML proliferation in vivo. GSK-3 $\alpha$ inhibition was anti-correlated with gene sets obtained by coexpression of HOXA9 and MEIS1 in hematopoietic cells. Furthermore, c-Myc expression and c-Myc-regulated genes were also downregulated upon GSK-3 $\alpha$ inhibition, which may be a mechanism of AML differentiation. 
The effects of inhibition of GSK-3 by lithium treatment has been examined in clinical trial with AML patients treated with cytosine arabinoside and daunorubicin. ${ }^{106}$ This clinical study demonstrated that the percentage of AML patients with complete remission was significantly lower in those patients who received lithium (75\% vs $49 \%$ ). These results suggest that more potent GSK-3 inhibitors might have greater anticancer effects, at least with some cancers. However, there remains concern that inhibiting GSK-3 may promote the growth of certain cancer types.

Another mechanism by which GSK-3 may impair differentiation in $A M L$ is its interaction with the retinoic acid receptor (RAR). ${ }^{107}$ RAR is impaired by rearrangement in the acute promyelocytic leukemia (APL) subtype (acute PML), which is characterized by the translocation $t(15 ; 17)$, RARA-PML. APL can be differentiated and cured by the RAR ligand all-trans retinoic acid. GSK-3 can phosphorylate and inactivate RAR, and GSK-3 inhibition enhances the differentiation potential of all-trans retinoic acid even in non-APL AML.

Recently, it has been demonstrated that there are complex interactions between Akt and FOXO3 levels in maintaining LICs. ${ }^{62}$ Low levels of Akt were associated with elevated levels of Forkhead box $\mathrm{O} 3$ (FOXO3) that were required to maintain the functionality and immature status of the LICs. Decreased levels of FOXO3 promoted differentiation, maturation and apoptosis of the MLL-AF9 LICs and improved animal survival. Decreased levels of FOXO were associated with increased levels of JNK/C-Jun activation in the resistant leukemia cells that persisted despite reduced levels of FOXO. JNK inhibitors could potentiate the effects of Akt activation or $\mathrm{FOXO} 3$ depletion and induce differentiation of the AML LICs. The authors have suggested that mTORC1 and GSK-3 $\beta$ may provide important signals between Akt and FOXOs that abrogated the effects of FOXO suppression. ${ }^{62}$

\section{TARGETING $\beta$-CATENIN IN CML}

Recently, it was shown that Wnt/ $\beta$-catenin signaling is necessary for CML LSC survival. $\beta$-Catenin inactivation has been demonstrated to target imatinib-resistant CML LSCs. ${ }^{108}$ Studies with $\beta$-catenin conditional knockout mice have determined that although $\beta$-catenin was required for the self-renewal properties of fetal HSCs, it was not required for the maintenance and self-renewal of adult HSCs.

Importantly, Heidel et al. ${ }^{108}$ demonstrated that the nonsteroidal anti-inflammatory drug indomethacin targets $\beta$-catenin and can be used to inhibit CML LSCs. $\beta$-Catenin inhibition may represent a novel approach to treat minimal residual disease that is due to the presence of imatinib-resistant CML LSCs. $\beta$-Catenin signaling is necessary for CML LSC maintenance but it is not required for the survival of the bulk population of CMLs (non-LSCs). Inactivation of the $\beta$-catenin gene (CTNNB1) was shown to hinder the development of CML. ${ }^{109}$ In the studies by Heidel et al. ${ }^{108}$ using a conditional $\beta$-catenin knockout mouse and BCR-ABL-infected BM cells, the combination of $\beta$-catenin loss and imatinib treatment reduced the serial transplantability of CML LSCs at least 100-fold. Although inhibition of Wnt/ $\beta$-catenin signaling suppressed CML LSC survival, it did not affect the survival of the bulk CML cells. Thus, $\beta$-cateninmediated downstream gene expression was necessary for the maintenance of the critical stemness/self-renewal properties of CML LSCs. Furthermore, the authors demonstrated that treatment with indomethacin potentiated the effects of imatinib as mice treated with both drugs had lower numbers of CML LSCs. In primary CML patient samples, reduced prostaglandin levels were associated with an increased response to imatinib.

Differentiated CML cells are addicted to the BCR-ABL oncoprotein and hence they are normally sensitive to $B C R-A B L$ inhibitors, provided they do not have mutations in the rearranged $B C R-A B L$ gene that confers resistance to such inhibitors. These cells are often referred to as the bulk leukemia cells. However, CML LSCs proliferate slowly and often display altered drug pump expression and resistance to $B C R-A B L$ inhibitors. Thus, although whereas the $B C R-A B L$ inhibitors will suppress the bulk CML cells, they will not eliminate the CML LSCs. Thus, the CML patient is dependent upon continued treatment with BCR-ABL inhibitors and may develop resistance to these inhibitors. Recently, a novel target (that is, the SIRT1 (silent information regulator 1) gene) has been identified that will synergize with $B C R-A B L$ inhibitors to result in the suppression of CML LSCs. SIRT1 is a member of the Sirtuin family of proteins that are a unique class of histone deacetylase inhibitors as their substrates can be either histones or nonhistone proteins. SIRT1 was determined to be expressed at higher levels in the CD34+ population of CMLs that was enriched in CML LSCs than in normal CD34 + cells. ${ }^{110}$ Knockdown of SIRT1 expression in CD34+ CML LSCs reduced their proliferation, increased apoptosis and decreased their colony-forming ability. In contrast, knockdown of SIRT1 had less effect on normal CD34+ cells. These results point to an important role of SIRT1 in CD34 + cells. In addition, the authors investigated the ability of the small-molecule p53 activator Tenovin 6 (TV-6) that inhibits the sirtuin family proteins to suppress CML LSCs. TV-6 enhanced the ability of imatinib to reduce colony formation and in vivo engraftment. SIRT1 will deacetylate p53 and regulate its transcriptional activity. ${ }^{110}$ Inhibition of SIRT1 increased p53 acetylation and transcriptional activity and increased the effectiveness of the BCR-ABL inhibitor imatinib on the CML LSCs. These effects would only be predicted to occur in patients with CML LSCs containing wild-type TP53. This approach would not be appropriate in CML patients with additional mutations at the $B C R$ $A B L$ gene that render them resistant to imatinib, or the $\sim 30 \%$ of blast crisis patients who have inactivating mutations in TP53. An overview of these events is presented in Figure 5.

Although not much is currently known about the interactions between GSK-3 and SIRT1, there are some reports describing some relationships between these protein families. SIRT1 can regulate the Wnt pathway including $\beta$-catenin. ${ }^{111}$

Loss of $\beta$-catenin impaired the renewal of normal and CML stem cells in mouse models. ${ }^{109}$ Interesting, in this study, loss of $\beta$-catenin did not inhibit the progression of acute lymphocytic leukemia in the CTNNB1-mutant mice.

Recently, it has been observed that the natural product berbamine inhibits calcium calmodulin-dependent kinase Il $\gamma$ (CaMKIl $\gamma$ ) that is a critical regulator in CML LSCs. ${ }^{112}$ Berbamine binds to the ATP-binding pocket of CaMKIl $\gamma$ and inhibits its activity. Berbamine is an ATP-competitive inhibitor of CaMKIll. CaMKIl $\gamma$ was determined to be highly active in CML LSCs and required for their proliferation and survival. In contrast, CaMKIl $\gamma$ was not as highly activated in HSCs. CaMKIl $\gamma$ co-activated the $\beta$-catenin and Stat3 signaling pathways. Berbamine inhibited the growth of imatinib-resistant CML LSC cells as well as those containing the T315I BCR-ABL mutation but not normal hematopoietic cells. Berbamine inhibited NF- $\kappa \mathrm{B}, \beta$-catenin and Stat3 signaling.

\section{ABERRANT GSK-3 $\beta$ MRNA SPLICING AND ITS EFFECTS ON B-CATENIN IN CML}

Aberrant GSK-3 $\beta$ mRNA splicing has been demonstrated to increase in $\beta$-catenin expression in blast crisis (BC) CML LSCs. This was reported to affect the replating ability of the CML LSCs. ${ }^{113}$ Previously, the authors had observed that higher levels of nuclearlocalized $\beta$-catenin were expressed in BC CML LSCs than in the granulocyte macrophage progenitor (GMP) pool from normal $\mathrm{BM}^{88}$ In this subsequent study, the complementary DNA sequences of a number of genes in the Wnt/ $\beta$-catenin pathway were examined, including $A P C, G S K 3 B, A X I N 1, C T N N B 1, L E F 1$, CCND1 and MYC. The authors examined the complementary DNA sequences of these genes in 15 normal, 4 chronic-phase, 1 accelerated-phase and 8 myeloid BC CML samples. Novel in-frame splice deletions were detected in BC CML GMPs that are enriched 
a

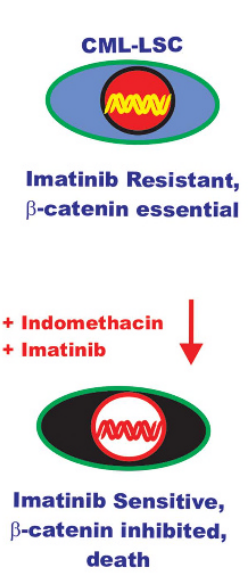

c

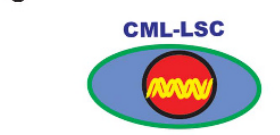

Imatinib Resistant, $\beta$-catenin essential for survival CaMKII regulation of $\beta$-catenin.

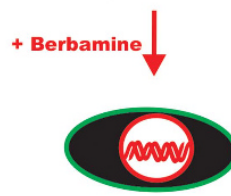

CaMKII inhibited, $\beta$-catenin inactive, cell death by apoptosis

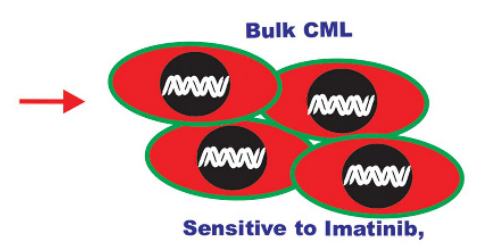

$\beta$-catenin not essential?

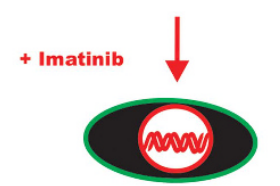

BCR-ABL inhibited, death

d

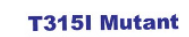
BCR-ABL CML

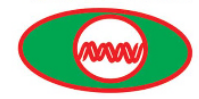

Imatinib Resistant.

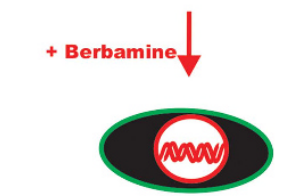

CaMKII inhibited, NF-KB, STAT3, $\beta$-catenin inactive, cell death by apoptosis b

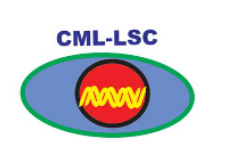

Imatinib Resistant, SIRT1 increased, p53 deacetylated?

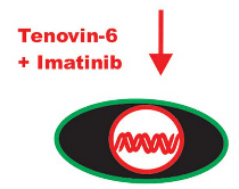

p53 acetylated, increased activity, sensitive to Imatinib, BCR-ABL inhibited,

$$
\text { death }
$$

e

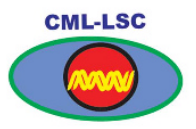

Imatinib Resistant, BCR-ABL regulates GSK-3, Imatinib increases GSK-3 activity and nuclear localization.

+ Imatinb

\& GSK3 Inhs.

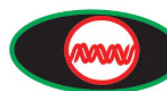

Induction of a pro-differentiation/apoptotic pathway via regulation of $\beta$-catenin, cyclinD1, C-EBP $\alpha$, ATF5, mTOR and p27Kip1
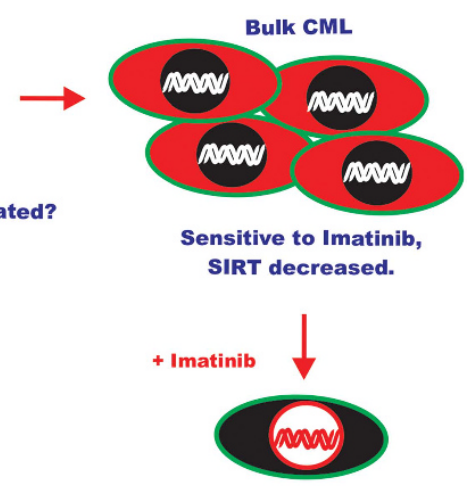

BCR-ABL inhibited, death f

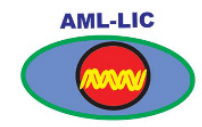

$\beta$-catenin essential for survival

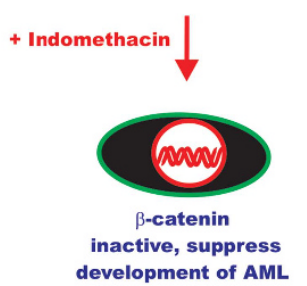

Figure 5. Novel approaches of targeting signaling pathways in leukemia. (a) Effects of indomethacin on CML-LSC. $\beta$-Catenin is essential in CMC LSCs that are resistant to imatinib, and treatment with indomethacin inhibits $\beta$-catenin and sensitizes the CML LSCs to imatinib. In contrast, in bulk CML $\beta$-catenin in not essential and cells are addicted to BCR-ABL and sensitive to BCR-ABL inhibitor imatinib. (b) Recently, it has been discovered that the activity of SIRT1, a NAD-dependent deacetylase, is increased in CML LSCs that are resistant to imatinib, whereas decreased levels are detected in bulk CMCs that are sensitive to imatinib. Also it has been shown that upon treatment of CML-LSC with Tenovin-6, a small-molecule activator of p53, p53 was acetylated and there was increased p53 activity and the CML LSCs became sensitive to imatinib. (c) The CaMKII pathway has been shown to be important in the regulation of $\beta$-catenin in imatinib-resistant CML LSCs. Treatment of CML LSCs with the natural product berbamine resulted in CaMKII and $\beta$-catenin inhibition and death of the CML LSCs. (d) Berbamine is also effective in inhibiting the growth of bulk CMLs containing the T315I-BCR-ABL mutation in part by inhibiting CaMKII, NF- $\kappa B$, $\beta$-catenin and STAT signaling pathways. (e) The combination of BCR-ABL and GSK-3 inhibitors has been shown to induce a pro-differentiation/apoptotic pathway in CML LSCs. (f) Indomethacin is also effective in inhibiting AML LICs and AML LSCs that are c-Kit high and dependent on $\beta$-catenin signaling. This figure is included to provide the reader some of the novel approaches to successfully target CML LSCs and AML LICs and the importance of $\beta$-catenin in the survival of both CML LSCs and AML LICs.

with LSCs. Aberrant GSK-3 $\beta$ splicing events were detected in four out of seven patient samples that resulted in deletions of exons 8 and 9. Exons 8 and 9 encode the FRAT (also known as GBP) and Axin binding domains, and their deletion resulted in the inability of GSK-3 $\beta$ to bind Axin and induce the phosphorylation and inactivation of $\beta$-catenin. Other in-frame splice domain mutations that resulted in loss of either exon 9 or 11 or exon 9 and 11 were detected in CML blasts as well as chronic-phase CML and normal peripheral blood, BM and cord blood, but in-frame splicing mutations resulting in deletion of exons 8 and 9 were not detected in these cell fractions. The GMP BC CMC cells with mutant GSK-3 $\beta$ had elevated levels of $\beta$-catenin and displayed increased serial engraftment capabilities. Introduction of a fulllength GSK-3 $\beta$ complementary DNA into the GMP BC CMC cells with the mutant GSK-3 $\beta$ splicing mutations reduced in vitro replating as well as leukemia engraftment.

\section{GSK-3 REGULATION OF RNA BINDING PROTEINS IMPLICATED IN CML LSCS}

Another target in CML LSCs is the RNA-binding protein Musashi2 that represses Numb. The Numb protein functions in cell fate by regulating asymmetric cell division, through degradation of Notch. Musashi1 and Musashi2 are highly related proteins and display $>90 \%$ identity at the amino sequence level in their RNA recognition motifs. Musashi2 is ubiquitously expressed, whereas Musashi1 displays a more limited expression pattern and is reported to be expressed in embryonic and adult neural stem cells. ${ }^{114}$ Musashi2 is expressed at higher levels in hematopoietic cells than Musashi1. Musashi2 expression was elevated in stem cells and was detected at 10-fold higher levels in immature BC CML. Musashi2 was most enriched in the lineagenegative fraction of BC CML. Musashi2 is thought to be a putative marker of cancer-initiating cells and its expression was higher in 
cells with high levels of total Wnt/ $\beta$-catenin signaling. ${ }^{115}$ An overview of the effects of Musashi2 on BC CML and the interactions with Numb and other signaling pathways is presented in Figure 6.

The Numb protein plays key roles in the determination of cell fate during development. Numb influences cell-fate decisions by suppressing the effects of Notch. Numb was originally identified as a cell-fate determinant in Drosophila development. The name Numb arose as loss of Numb activity in Drosophila resulted in a deficiency of sensory neurons; hence, the flies were 'Numb'. Numb has important roles in maintenance of the normal stem cell compartment. It can regulate the Notch, p53, Hh and other pathways and is considered a tumor-suppressor gene. It is involved in asymmetric cell division. Musashi represses Numb by binding the $3^{\prime}$ untranslated region of the Numb mRNA. In the chronic phase of $\mathrm{CML}$, high levels of Numb were detected, whereas in the BC stage, lower levels of Numb were observed. ${ }^{116}$ In addition, the Reya group ${ }^{116}$ observed that ectopic expression of Numb promoted differentiation of CML and impaired advancedphase CML. Furthermore, they demonstrated that an oncogene associated with the blast phase of CML, NUP98-HOXA9, triggered the expression of Musashi2, which in turn repressed Numb. Musashi2 expression was determined to be upregulated during human CML progression and was also an early indicator of a poorer prognosis. Decreased Numb expression in BC-phase CML suggests that low levels of Numb may be essential for maintaining the CML cells at an immature stem-like phenotype. These studies suggest that a potential therapy of CML-LSC cells could be to increase Numb levels in cells that would trigger differentiation and then treatment with imatinib to inhibit disease progression.

Numb can antagonize Notch signaling. GSK-3 $\beta$ can also inhibit Notch signaling. ${ }^{117}$ Notch signaling is elevated in BC CML. ${ }^{116}$

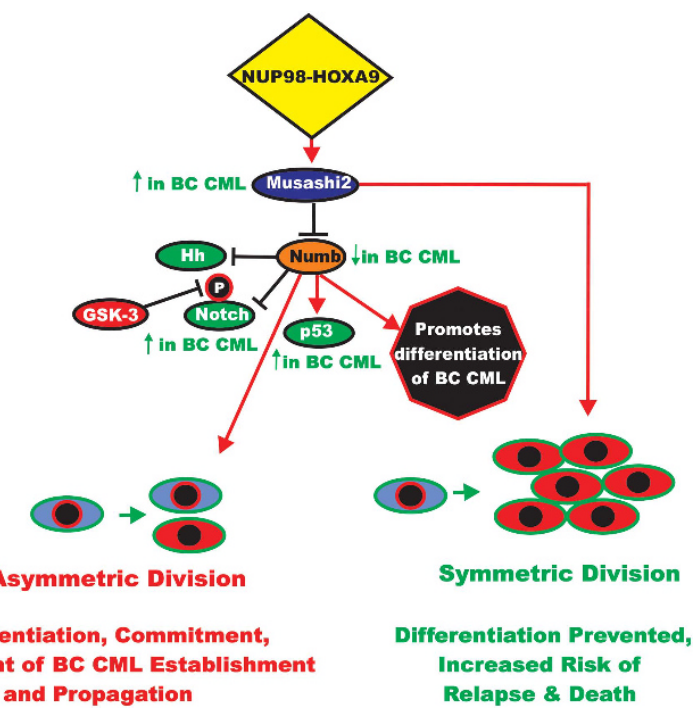

Figure 6. Roles of Musashi and Numb in regulation of asymmetric and symmetric cell division in BC CML. Chimeric upstream transcription factors such as NUP98-HOXA9 can induce the Musashi RNA binding factor that is important in determining cell fate. Musashi is elevated in $\mathrm{BC} C M L$; in contrast, the Numb protein is detected at low levels in BC CML. The Numb protein plays a key role in asymmetric cell division and it is usually present in one daughter cell after division and not the other, allowing different cellular fates. Numb can regulate many pathways important in BC CML including $\mathrm{Hh}$, Notch and p53 that can also be regulated by GSK-3. This figure is presented to provide the reader an idea of the importance of regulation of asymmetric vs symmetric division in BC CML and how division can be regulated by Numb and upstream Musashi and NUP98-HOXA9.
Numb expression can reduce the incidence and propagation of $B C$ CML. p53 is a target of Numb. p53 levels were higher in Numb-expressing BC CML and the inhibitory effects of Numb were dependent on functional p53 activity. NUP98-HOXA9 induced the expression of Musashi2 that resulted in decreased Numb expression that contributed to BC CML. Genetic studies have indicated that loss of Musashi2 expression impaired leukemia in genetically mutated (gene trap) mice lacking the Musashi2 gene. The effects of shRNA knockdown of Musashi2 were also determined. Transfection of established BC CML with shMusahi2 increased the expression of Numb and reduced leukemic growth in vitro and also resulted in more differentiated CML cells that displayed decreased ability to propagate the disease. The authors concluded that Musashi2 is important for the establishment and propagation of BC CML. ${ }^{116}$

The authors of this important study examined the expression of Musashi2 in CML patients. Musashi2 was determined to be expressed at higher levels in BC CML patients whereas Numb was downregulated. As many $B C C M L$ patients contain mutations at other genes, the authors also examined the expression of HOXA9 in CML patients. HOXA9 expression was also elevated in $B C$ patients that may result in the increased expression of Musashi2. HES1 and TRIP, which are targets of Notch signaling, were also upregulated in the BC CML patients. The authors determined that increased Musashi2 expression was associated with a higher risk of relapse and a higher risk of death. Thus, Musashi2 expression may be an early marker of advanced CML disease. Although BCR-ABL did not appear to affect the decision of asymmetric or symmetric division, NUP98-HOXA9 promoted symmetric division, thus preventing differentiation. In contrast, Numb expression drives asymmetric division that could lead to commitment, differentiation and impairment of BC CML establishment and propagation. ${ }^{116}$ The effects of Musashi and Numb may be mediated through the Notch and p53 pathways. ${ }^{18,119}$ GSK-3 $\beta$ can regulate both pathways.

\section{GSK/ $\boldsymbol{\beta}$-ARRESTIN2 AND CML DEVELOPMENT}

Another key component in the establishment of $\mathrm{CML}$ is $\beta$-arrestin2 $\left(\beta\right.$-arr2). ${ }^{120} \beta$-arr2 is a member of a small family of scaffolding proteins that regulate $\mathrm{G}$ protein-coupled receptor signaling. They were originally identified as desensitizers of $G$ protein-coupled receptor signaling; however, they now have been shown to transduce signals. The $\beta$-arr2 interacts and regulates many signal transduction pathways that are important in proliferation and differentiation. The $\beta$-arrs have been shown to be important in regulation of the Raf/MEK/ERK and PI3K/PTEN/Akt/mTOR proliferative pathways as well as the $\mathrm{Wnt} / \beta$-catenin and $\mathrm{Hh}$ developmental pathways. ${ }^{121,122}$

GSK-3 $\beta$ is a key regulatory molecule essential for $\beta$-arr 2 complex formation. GSK-3 $\beta$ stabilizes the $\beta$-arr2 complex. Akt normally inhibits the activity of GSK-3 $\beta$; Akt can be inhibited by PP2A. Lithium inhibits GSK-3 by activating Akt. ${ }^{123}$ In the presence of activated Akt, GSK-3 $\beta$ is inhibited and the $\beta$-arr2 signaling complex is destabilized. GSK-3 $\beta$ is essential for the effects that lithium has on mammalian behavioral disorders at least in mice. ${ }^{123}$ Thus, GSK-3 and $\beta$-arr2 could be key targets in leukemia and other disorders.

Upon analysis of $\beta$-arr $1^{-/-}$or $\beta$-arr $2^{-/-}$knockout mice, it was determined that the HSC-enriched cells (c-Kit + Lin - , Sca- $1+$ (KLS)) in both $\beta$-arr ${ }^{-1-}$ and $\beta$-arr2 ${ }^{-/-}$null mice were similar to those present in normal mice, indicating that the establishment of the hematopoietic compartment was not dependent upon either functional $\beta$-arr 1 or $\beta$-arr2. ${ }^{120}$ However, in the $\beta$-arr2 ${ }^{-/-}$knockout mice, defects in the functions of the HSCs were observed, as well as in the frequency of colonies observed after serial replating. Also, the HSCs from $\beta$-arr $2^{-1-}$ mice had a decreased ability to renew and repopulate lethally irradiated recipient mice in 
comparison with HSCs isolated from normal mice. Thus, long-term HSC renewal was dependent on functional $\beta$-arr2 activity under conditions where a high degree of proliferation was required but not during homeostasis. ${ }^{120}$

To ascertain whether $\beta$-arr2 had a role in leukemia development, KLS stem cells were isolated from wild-type, $\beta$-arr $1^{-/}$and $\beta$-arr ${ }^{-/-}$mice and infected with a virus encoding $B C R-A B L$ and serially replated in vitro. Fewer colonies were obtained from the KLS cells obtained from the $\beta$-arr $2^{-1-}$ mice. Additional studies were performed in transplant studies in mice. Fewer mice transplanted with the $B C R-A B L$-infected KLS cells obtained from $\beta$-arr2 $2^{-1-}$ succumbed to disease. Thus, $\beta$-arr2 plays key roles in the establishment of $C M L$ in vitro and in vivo. Additional studies were performed with $B C R A B L$-infected KLS cells from normal mice that were transduced with $\beta$-arr2 shRNAs or control shRNAs. Significantly fewer colonies were recovered from CML stem cells transduced with the $\beta$-arr2-shRNAs. These studies indicate that $\beta$-arr2 was required for both initiation of CML and growth and maintenance of the disease. Loss of $\beta$-arr2 also resulted in decreased levels of $\beta$-catenin. ${ }^{120}$

To determine whether $\beta$-arr2 had roles in $B C C M L, B C R A B L-$ infected KLS cells were infected with the NUP98-HOXA9 oncogene that results in cells that have properties related to BC CML. NUP98HOXA9 is a chromosomal translocation detected in BC CML as well as in AML. ${ }^{124}$ The combination of $\beta$-arr2 deficiency, BCR-ABL and NUP98-HOXA9 expression decreased primary and secondary colony formation in vitro as well as establishment of BC CML in vivo compared with cells from normal and $\beta$-arr2-mutant mice. These results indicated that $\beta$-arr2 expression was necessary for establishment of the more aggressive BC phase of CML. ${ }^{120}$ Studies performed with shRNA specific for $\beta$-arr2 indicated that knockdown of $\beta$-arr2 in BCRABL- and NUP98-HOXA9-transduced $B C C M L$ cells resulted in the differentiation of the BC CML cells and exhaustion of the CML LSC population and impairment in the disease progression. Loss of $\beta$-arr 2 reduced activation of $\beta$-catenin and Wnt-related targets in CML and BC CML. Thus, $\beta$-arr2 is a unique molecular target in certain leukemias and potentially other cancers. These studies indicated that $\beta$-arr2 is a key multifunctional adaptor protein that cooperated with $B C R A B L$ and potentially other oncogenes to induce the $C M L$, and perhaps other cancers, to become more aggressive. ${ }^{120}$

\section{WNT/ $\beta$-CATENIN PATHWAY IN AML}

The Wnt/ $\beta$-catenin pathway has been implicated in $A M L$ and is required for the development of AML LSC. ${ }^{125}$ The Armstrong group $^{125}$ investigated LSCs in mouse models of AML. ${ }^{125}$ The LSC AML models were induced either by the coexpression of the Hoxa9 and Meis1a oncogenes or by the fusion of MLL-AF9 oncogene. The $\mathrm{Wnt} / \beta$-catenin pathway was required for self-renewal of LSCs that were derived from either HSCs or more differentiated GMP cells. The Wnt/ $\beta$-catenin pathway is normally active in HSCs but not in more differentiated GMPs. To determine whether GMPs and LSCs differed in their ability to be transformed by HoxA9 and Meis1a, the cells were co-transduced with HoxA9 and Meis $1 a$ genes and then sorted for KLS cells, which are enriched with LSCs, and for Lin-, c-Kit +, Sca-1-, FcR $\gamma+$, CD34 + cells that are enriched with GMP cells. The GMP-HoxA9/ Meis1a cells differed from KLS-HoxA9/Meis1a cells as the GMP-HoxA9/Meis1a cells rarely developed leukemia in mice, whereas the KLS-HoxA9/Meis1a did. Similar studies with GMPMLL-AF9 cells indicated that they developed leukemia in $\sim 70 \%$ of the mice. Some of the in vivo defects in the GMP-HoxA9/Meis1a cells were examined in recipient mice. Although both KLS-HoxA9/ Meis $1 a$ and GMP-HoxA9/Meis $1 a$ cells homed to the BM, and both cell types had heterogeneity in terms of the expression of the stem cell marker, c-Kit (high and low c-Kit populations), the GMP-
HoxA9/Meis1a cells only maintained the c-Kit-low population for $\sim 1$ month after transplantation in mice, whereas the KLS-HoxA9/ Meis $1 a$ cells retained the high and low c-Kit populations and eventually the transplanted mice succumbed from leukemia. A high frequency of LICs was detected in the c-Kit high population, whereas a low frequency of LICs was observed in the cells that expressed low levels of c-Kit. In addition, the GMP/ MLL-AF9 cells were enriched with LSCs. The authors also investigated some of the genes that were differentially expressed in normal HSCs, LSCs and normal myeloid progenitor cells. Cyclooxygenase-1 (Cox1) is also known as prostaglandin $\mathrm{G} / \mathrm{H}$ synthase 1 and its gene name is PTGS1. PTGS1 and prostaglandin receptor (PTGER1) were upregulated in GMP-MLL-AF9 and KLS-HoxA9/Meis1a-derived L-GMPs. ${ }^{125}$

There have been previously connections documented between the $W n t / \beta$-catenin and prostaglandin synthesis pathways. ${ }^{126}$ The expression of $\beta$-catenin was observed in GMP-MLL-AF9-derived and KLS-HoxA9/Meis1a-derived L-GMPs but not in normal GMP. $\beta$-Catenin was also not detected in GMP-HoxA9/Meis1a cells. Activated $\beta$-catenin was detected after 1 month in the nucleus of c-Kit-high but not c-Kit-low cells isolated from mice injected with KLS-HoxA9/Meis $1 a$. A constitutively active $\beta$-catenin (CTNNB1) gene cooperated with GMP-HoxA9/Meis1a cells to induce AML as frequently as that observed in KLS-HoxA9/Meis $1 a$ cells. As a control, the ability of the constitutively active $\beta$-catenin (CTNNB1) gene by itself to induce AML was determined and it did not. ${ }^{125}$

The effects of indomethacin were determined. Treatment of LIC-enriched c-Kit-high cells with indomethacin lowered $\beta$-catenin expression in vitro and lowered the expression of $\beta$-catenin in mice injected with the LICs. Indomethacin treatment also lowered the presence of the c-Kit-high LSC population in mice transplanted with fully developed MLL-AF9 leukemia. These stunning results indicated that indomethacin suppressed the LIC population necessary for the development of $\mathrm{AML}$ as well as reduced established LSCs. ${ }^{125}$

The role of $\beta$-catenin in HoxA9/Meis1a-mediated leukemia was further examined with $\beta$-catenin-deficient KLS cells obtained from BM of CTNNB1-loxP/loxP mice. KLS-HoxA9/Meis1a, CTNNB1 loxP/loxP cells were isolated and transduced with the Cre recombinase or an empty vector. The resulting KLS-HoxA9/Meis1a, CTNNB1 $1^{-1-}$ cells were injected into mice as were KLS-HoxA9/Meis1a, CTNNB1-loxP/loxP cells. The KLS-HoxA9/ Meis $1 a, C T N N B 1^{-1-}$ cells lost their ability to expand in mice, whereas the KLS-HoxA9/Meis1a, CTNNB-loxP/loxP cells expanded in mouse BM and induced leukemia. Introduction of the constitutively active CTNNB1 construct allowed the KLS-HoxA9/ Meis $1 a$, CTNNB1 $^{-1-}$ cells to proliferate. ${ }^{125}$

Thus, the Wnt/ $\beta$-catenin pathway was required for Hoxmediated transformation of HSCs and MLL-AF9-mediated transformation of committed progenitor cells. MLL-AF9 activated CTNNB1 in GMP to allow transformation. In contrast, there was normally insufficient $\beta$-catenin in normal GMP to permit the $H O X$ genes to transform GMP. These results by the Armstrong group ${ }^{125}$ suggest that targeting the $\mathrm{Wnt} / \beta$-catenin pathway is a therapeutic approach in AML as the $\beta$-catenin is not absolutely required for the self-renewal of adult HSCs. ${ }^{104,125}$

\section{ROLES OF GSK-3/WNT/B-CATENIN IN CML AND OTHER LEUKEMIAS}

GSK-3 has also been shown to be a therapeutic target in MLL, CLL and MM. GSK-3 plays key roles in CML-LSC and may be a therapeutic target. The ability of CML LSCs to renew has been linked to Wnt/ $\beta$-catenin activation as a result of GSK-3 $\beta$ inhibition or BCR-ABL-mediated phosphorylation of $\beta$-catenin. BCR-ABL phosphorylation of $\beta$-catenin impaired the ability of $\beta$-catenin to bind the GSK-3/Axin destruction complex. ${ }^{88,113,127}$ GSK-3 $\beta$ is 
activated by phosphorylation at Y216 that is located in the activation loop. This may occur by autophosphorylation or phosphorylation mediated by PYK2, MEK1 or SRC-family kinases. $\beta$-Catenin is also associated with imatinib resistance in CML. ${ }^{88}$

Recently, it has been observed that targeting GSK-3 $\beta$ promotes imatinib-mediated apoptosis in CML LSCs but not normal HSCs. ${ }^{128}$ GSK-3 $\beta$ is constitutively phosphorylated on Y216 and predominantly localized in the cytoplasm in CML stem/progenitor cells that contrasts with the cytoplasmic/nuclear localization and activation status of GSK-3 $\beta$ in normal cells. BCR-ABL can regulate the activation of the Raf/MEK/ERK pathway and Src/ GSK-3 $\beta$. Imatinib treatment increased GSK-3 $\beta$ activity and nuclear transport. In contrast, dasatinib, which targets both BCR-ABL and cytokine-dependent Raf/MEK/ERK pathway and Src/GSK-3 $\beta$, did not increase GSK-3 $\beta$ activity and nuclear transport. These studies revealed that treatment of CML LSCs with the GSK-3 $\beta$ inhibitor SB216763 and imatinib suppressed CML LSCs and spared BCR-ABL-negative cells. In contrast, treatment of CML LSCs with the GSK-3 inhibitor SB216763 and dasatinib did not suppress CML LSCs. Thus, GSK-3 inhibition primed a pro-differentiative/pro-apoptotic transcription program in the nucleus of CML LSCs by regulating the levels of $\beta$-catenin, cyclin $\mathrm{D} 1, \mathrm{c}-\mathrm{EBP} \alpha, \mathrm{ATF} 5, \mathrm{mTOR}$ and $\mathrm{p} 27^{\mathrm{Kip}-1}$.

In the above studies by Reddiconto et $a l^{128}$, freshly isolated CML LSCs expressed a constitutively Y216-phophorylated GSK-3 $\beta$ that could be inhibited by the ATP-competitive GSK-3 $\beta$ inhibitor SB216763. Inhibition of GSK-3 $\beta$ decreased the pool of $\beta$-catenin that was targeted for proteasomal degradation. Furthermore, imatinib induced the phosphorylation of GSK-3 $\beta$ at Y216 in a dose-dependent manner. These studies also indicated that Src family kinases and Raf/MEK/ERK signaling were upstream regulators of GSK-3 $\beta$ activity in cytokine-stimulated CML chronicphase precursors. GSK-3 $\beta$ was shown to be located primarily in the cytoplasm and its nuclear levels were reduced in cytokinestimulated CML LSCs. In contrast, a diffuse staining of GSK-3 $\beta$ was observed in normal HSCs, indicating that it was shuttling in and out of the nucleus. Its translocation may have been aided by chaperon proteins such as FRAT or tau. In the previously mentioned studies by Reddiconto et al. ${ }^{128}$, the nuclear import of GSK-3 $\beta$ was prevented in a BCR-ABL-dependent mechanism. Combining GSK-3 inhibitors with imatinib, but not dasatinib, resulted in changes in the levels of $\beta$-catenin, cyclin $\mathrm{D} 1, \mathrm{C} / \mathrm{EBP} \alpha$, ATF5, mTOR and $\mathrm{p} 27^{\mathrm{Kip}-1}$ in CML LSCs. The authors have proposed that targeting of GSK-3 $\beta$ in the presence of imatinib may prime a differentiation/apoptotic program in CML LSCs. As dasatinib also inhibited Src and Src-family kinase signaling, it may have prevented the differentiation/apoptotic program and thus was ineffective in therapy in this case.

\section{EFFECTS OF GSK-3 IN B-CLL}

Inhibition of GSK-3 in B-CLL resulted in epigenetic silencing of $\mathrm{NF}-\kappa \mathrm{B}$ target genes and induction of apoptosis as well as suppression of proliferation. ${ }^{129}$ GSK-3 $\beta$ positively regulated NF- $\kappa B$ gene transcription and cell survival. GSK-3 inhibition resulted in inhibition of $\mathrm{NF}-\kappa \mathrm{B}$ binding to some of its target gene promoters ( $\mathrm{Bcl}-2$ and $\mathrm{X}$-linked inhibitor of apoptosis (XIAP)) via epigenetic modification of histones.

\section{EFFECTS OF GSK-3 IN MULTIPLE MYELOMA}

Both GSK-3 $\alpha$ and GSK-3 $\beta$ have been determined to be expressed in multiple myeloma (MM). ${ }^{130,131}$ GSK-3 inhibition also suppressed MM proliferation. GSK-3 inhibitor treatment resulted in dephosphorylation of FOXO-3A and activation of $\mathrm{p} 27^{\mathrm{Kip}-1}$. In untreated MM cells, FOXO-3A was highly phosphorylated and inactive. ${ }^{132}$

Thiadiazolidinone (TDZD) is a noncompetitive inhibitor of GSK-3. TDZD induced apoptosis in MM cell lines as well as apoptosis of primary myeloma cells freshly isolated from patients. In contrast, CD34 + normal hematopoietic cells were protected from apoptosis after TDZD treatment. The expression of the pro-apoptotic proteins Fas ligand and $1-\kappa B \alpha$ increased after TDZD treatment. Other studies have examined the role of GSK-3 inhibitors in MM. ${ }^{130}$ GSK-3 inhibition arrested MM cell proliferation and induced apoptosis. MM cell viability was reduced after treatment with small interfering RNAs for GSK-3 $\beta$ but not for GSK$3 \alpha$. Interestingly, inhibition of GSK-3 $\alpha$ sensitized the MM cells to the cytotoxic effects of the proteosome inhibitor bortezomib. Bortezomib treatment resulted in the nuclear translocation of S9- and S21-dephosphorylated GSK-3 $\beta$ and GSK-3 $\alpha$ respectively. GSK-3 $\alpha$ knockdown resulted in reduced phosphorylation of Akt at S473. Thus, Akt may regulate GSK-3 and GSK-3 may regulate Akt.

GSK-3 has been proposed to have growth-promoting roles in MM as it may support their survival as well as favor loss by acting on the microenvironment. The microenvironment supports MM growth and also protects against cytotoxic agents. GSK-3 may phosphorylate the MAF family of transcription factors that promote proliferation of MM. The MAF family of transcription factors are important in MM as the three MAF genes have been shown to be translocated to the IgH locus in MM. Namely, CMAF in $t(16: 14)$, MAFB in $t(20 ; 14)$ and MAFA in $t(8: 14))^{133}$ GSK-3 phosphorylation of MAFA resulted in a reduction of the half-life of the MAFA transcription factor as it underwent ubiquitindependent proteasomal degradation. However, GSK-3 phosphorylation of MAFA stimulated its transcriptional activity by enhancing its association with transcriptional co-activators. These results were conserved with $\mathrm{CMAF}$ and MAFB. ${ }^{133}$ The transforming ability of MAFA was dependent on GSK-3 phosphorylation. GSK-3 could activate Akt and $\mathrm{Mcl}-1$ that also resulted in proliferation and survival of $\mathrm{MM}$ and sensitivity to proteosome inhibitors. GSK-3 can also activate NF-KB that has many effects on proliferation, survival, resistance to chemotherapy and angiogenesis. In addition, GSK-3 inhibition of the Wnt/ $\beta$ catenin pathway could affect the ability of pre-osteoblasts to differentiate into osteoblasts that affect $\mathrm{MM}$-associated bone disease. GSK-3 inhibitors were determined to have two different effects on MM: first, they would inhibit the growth of MM and, second, they would suppress bone disease. Inhibition of GSK-3 by the $\mathrm{BIO}$ inhibitor (6-bromoindirubin-3'oxime) reduced the MMassociated bone disease in a mouse model. BIO induced apoptosis of $\mathrm{MM}$ cells in vitro and, more importantly, BIO improved osteogenic differentiation and enhanced bone deposition in mouse studies. ${ }^{134}$

Additional studies have suggested that GSK-3 plays prosurvival roles in $\mathrm{MM}$ through regulation of noncanonical NF- $\mathrm{KB}$ pathway expression and protein stability. ${ }^{135}$ Constitutive activation of the noncanonical NF- $\mathrm{KB}$ pathway has been observed in MM. GSK3 may interact with $\mathrm{Fbxw} 7 \alpha$ and regulate the degradation of p100 (NF- $\kappa B 2$ ), an inhibitor of noncanonical NF- $\kappa B$ signaling. Fbxw7 $\alpha$ is a F-box protein. F-box proteins are the substrate-targeting subunits of SCF (Skp1/Cul1/F-box protein) ubiquitin ligase complexes. p100 shuttles between the cytoplasm and nucleus. p100 is the primary inhibitor of noncanonical NF- $\kappa B$ pathway by sequestering $\mathrm{NF}-\mathrm{KB}$ heterodimers in the cytoplasm and preventing them from being localized in the nucleus and transcriptionally active. p100 is targeted in the nucleus for proteasomal degradation by $\mathrm{Fbxw} 7 \alpha$ when p100 is phosphorylated by GSK-3. Hence, inhibiting GSK-3 prevents p100 degradation and allows p100 to suppress noncanonical NF- $\kappa B$ signaling and apoptosis of MM occurs.

\section{GSK-3 INHIBITORS}

Previous clinical studies have indicated that lithium had effects on HSCs and other hematopoietic cells. ${ }^{136}$ Lithium was determined to increase circulating HSCs and peripheral blood counts. ${ }^{137}$ As early 
as 1998 , it was proposed that lithium might be used to mobilize HSCs for BM transplantations. ${ }^{137}$ An important effect of inhibiting GSK-3 is stimulation of the Wnt/ $\beta$-catenin and PI3K/PTEN/Akt/ mTORC1 pathways, although it must be pointed out that GSK-3 has many biological effects. ${ }^{138}$

Several (more than 50) GSK-3 inhibitors have been developed, including SB-216763, SB-415286, BIO and AR-A014418. ${ }^{139}$ GSK-3 inhibitors may be useful in the treatment of certain cancers. Some studies in colorectal cancer, glioblastoma, pancreatic cancer, MM, acute lymphocytic leukemia, AML, CLL and ovarian cancer have suggested that GSK-3 was involved in tumorigenesis. It may be appropriate to treat these cancers with GSK-3 inhibitors. ${ }^{129}$ Treatment of the leukemia cell lines KG1a, K562 and CMK with the GSK-3 inhibitor SB-415286 induced cell growth inhibition, cell cycle arrest at $G_{2} / M$, cyclin B downregulation, $\beta$-catenin stabilization, GSK-3 $\beta$ S9 phosphorylation and apoptosis. ${ }^{140}$ The authors observed that blocking the death receptor pathway with an inhibitor of caspase 8 did not neutralize the effects of the GSK-3 inhibitor. Treatment with the GSK-3 inhibitor resulted in the depolarization of the mitochondrial membrane potential that was regulated by the dephosphorylation of $\mathrm{BCl}-2$ and the downregulation of $\mathrm{BCl}-\mathrm{X}_{\mathrm{L}}$. It is unclear whether the stabilized $\beta$-catenin induced by the treatment of the leukemia cells with the GSK-3 inhibitor was responsible for the induction of apoptosis of these cells. This GSK-3 inhibitor (SB-415286) in the abovementioned studies as well as arsenic trioxide and $\mathrm{LiCl}$ inactivated GSK-3 $\beta$ in AML (APL) cells by inducing the phosphorylation of S9 on GSK-3 $\beta .{ }^{141}$ In contrast, in other cancers such as breast cancer and medulloblastoma, increased GSK-3 expression was associated with the induction of apoptosis. ${ }^{142}$ Thus, it remains controversial as to whether GSK-3 inhibitors will inhibit or promote cancer growth.

GSK-3 inhibitors have been isolated and their effects on pluripotency determined. Most GSK-3 inhibitors are ATP competitive and do not discriminate between GSK-3 $\alpha$ and GSK-3 $\beta .^{23}$ The $1 \mathrm{i}$ is a macrocyclic bisindolylmaleimide compound that is a selective ATP competitive inhibitor of GSK-3. BIO and TWS119 are additional GSK-3 inhibitors. BIO was determined to be capable of inhibiting GSK-3 and activating Wnt/ $\beta$-catenin signaling that maintained the pluripotency of human and mouse ESCs. ${ }^{102}$ Sustained GSK-3 inhibition or Wnt pathway activation was subsequently shown to promote ESC differentiation into multipotent mesendodermal progenitors or their differential progenitors. ${ }^{143}$ GSK-3 is a key component of the Wnt, $\mathrm{Hh}$ and Notch pathways that can regulate cell-fate determination and maintenance of stem cells. GSK-3 can phosphorylate the GLI2 transcription factor, a critical component in the Hh signaling pathway. ${ }^{144}$

Inhibition of GSK-3 in the presence of leukemia inhibitory factor and bone morphogenetic protein can enhance the self-renewal of ESCs in culture systems. The mechanism by which this happens is not clear. It may occur by preventing the downregulation of pluripotency factors such as Oct-4 and Nanog. In addition, other transcription factors associated with pluripotency, such as c-Myc and c-Jun, are phosphorylated and inactivated by GSK-3. Bone et al. ${ }^{145}$ synthesized 48 derivatives of the GSK-3 inhibitor $1 \mathrm{i}$. The ability of the GSK-3 inhibitors to maintain undifferentiated ESCs was determined. The effectiveness of these compounds to maintain undifferentiated ESCs was associated with inhibition of GSK-3. These results point to the potential of using GSK-3 inhibitors to maintain stem cell pluripotency as well as to expand these cells. These inhibitors may also prove to be effective with induced pluripotent stem cell generation.

The GSK-3 inhibitors GSK-3 IX, SB216763 and allsterpaullone inhibited the growth of human leukemias containing MLL translocations. ${ }^{36}$ GSK-3 $\beta$ activity has been shown to be essential for the maintenance of MLL LSCs but not normal myeloid progenitors or progenitors transfected with other non-MLL fusions. In these studies, both GSK- $3 \alpha$ and GSK-3 $\beta$ provided similar functions in terms of regulating the growth of MLL-transformed leukemias. The authors observed that the cell cycle regulatory molecule $\mathrm{p} 27^{\mathrm{Kip}-1}$ was important for the effectiveness of the GSK-3 inhibitors, as knockdown of $\mathrm{p} 27^{\mathrm{Kip}-1}$ suppressed the growth arrest of the GSK-3 inhibitors specifically in MLL-transformed cells but not fusion protein-transformed cells. The authors have proposed a model that GSK-3 supports the maintenance of $M L L$ leukemic cells by promoting $\mathrm{p} 27^{\mathrm{Kip}-1}$ degradation. In contrast, when the MLL-transformed cells were treated with the GSK-3 inhibitors, p2 $7^{\text {Kip-1 }}$ accumulated specifically in the MLL-transformed cells and cell cycle arrest occurred. Targeting the Raf/MEK/ERK and PI3K/PTEN/Akt/mTORC1 pathways will also have effects on GSK-3 activity as GSK-3 interacts with multiple components of these pathways. ${ }^{146-149}$ A diagram of some of the effects of GSK-3 inhibitors is presented in Figure 7.

\section{WNT/ $\boldsymbol{\beta}$-CATENIN INHIBITORS}

Inhibitors to the Wnt signaling pathway have been developed and are being evaluated. ${ }^{150}$ Some recent screens have demonstrated the iron dependence of $\beta$-catenin. ${ }^{151}$ Iron chelation may be an effective mechanism to inhibit Wnt/ $\beta$-catenin signaling. Multiple iron chelators have been developed and some have been evaluated in clinical trials for other diseases besides cancer. ${ }^{152}$

Iron chelators inhibit $\beta$-catenin stabilization. Acyl hydrazones bind iron and their chelating activity was required to block the growth of colorectal cancers that proliferate in response to increased $\mathrm{Wnt} / \beta$-catenin signaling. A series of structurally unrelated iron chelators consisting of desferioxamine, defarasirox and ciclopirox olamine inhibited Wnt signaling. AML patients taking ciclopirox olamine had a reduction in the expression of the Wnt target gene Axin-2. Increases in iron in certain cancers and growth conditions promoted elevated Wnt/ $\beta$-catenin signaling, resulting in tumorigenesis. ${ }^{151}$ Nonsteroidal anti-inflammatory drugs and the COX-2 inhibitor celecoxib inhibit $\beta$-catenindependent transcription in colorectal cancers and other cell types including leukemia. ${ }^{153}$

A critical complex to target in this pathway is the $\beta$-catenin/TCF complex. Unfortunately, this complex has been difficult to effectively target. An alternative approach is to activate natural inhibitors of this pathway. Inhibitors of Wnt response (IWR-1/2) have been isolated that target Axin and stabilize it. ${ }^{150}$ XAV939 is another Axin activator. ${ }^{154}$ IWR-1/2 and XAV939 stimulate $\beta$-catenin degradation by inhibiting tankyrase. The stability of Axin $1 / 2$ is regulated by ADP ribosylation that is catalyzed by the enzyme tankyrase. The turnover of Axin $1 / 2$ is regulated by poly-ADPribosylation that is catalyzed by tankyrase (TNKS). Thus, when tankyrase is inhibited, Axin is stabilized and $\beta$-catenin is destabilized and Wnt signaling is inhibited. The poly-ADPribosylated Axin1/Axin2 proteins are then recognized by proteins such as ring finger protein 146 (RNF146) that mediates their ubiquitination and subsequent degradation.

The stability of $\beta$-catenin is also negatively regulated by phosphorylation by CK1 $\gamma$. Thus, a mechanism to negatively regulate $\beta$-catenin stability is to increase $\mathrm{CK} 1 \gamma$ activity. It has been recently shown that the FDA (Food and Drug Administration)-approved drug Pyrvinium activated CK1 $\gamma$ and inhibited the $W n t / \beta$-catenin pathway. ${ }^{154}$ This was determined by performing a screen for compounds that could stabilize Axin and promote $\beta$-catenin turnover.

Another approach to inhibit the Wnt/ $\beta$-catenin pathway is to block the activity of the enzyme Porc (short for porcupine). ${ }^{67}$ Porc is a highly conserved component of the canonical Wnt/ $\beta$-catenin pathway. Porc is a transmembrane O-acyltransferase in the endoplasmic reticulum that is required for Wnt palmitoylation and maturation. ${ }^{155}$ Wnt proteins that lack lipids are not secreted. The IWP2 compound blocked Porc preventing Wnt palmitoylation and Wnt/ $\beta$-catenin signaling was suppressed. ${ }^{92}$ There are 
a

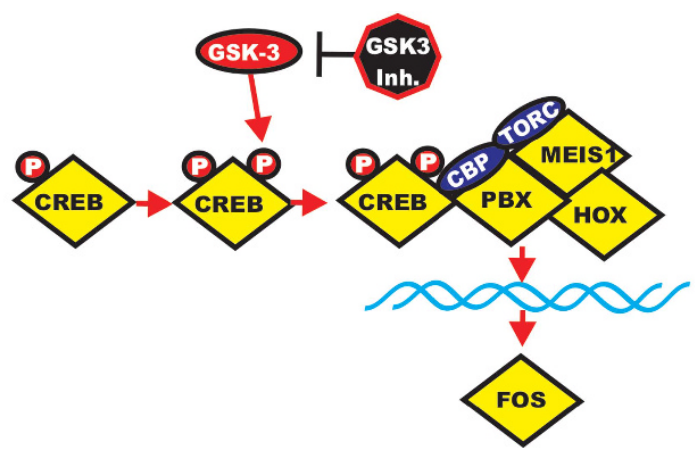

b
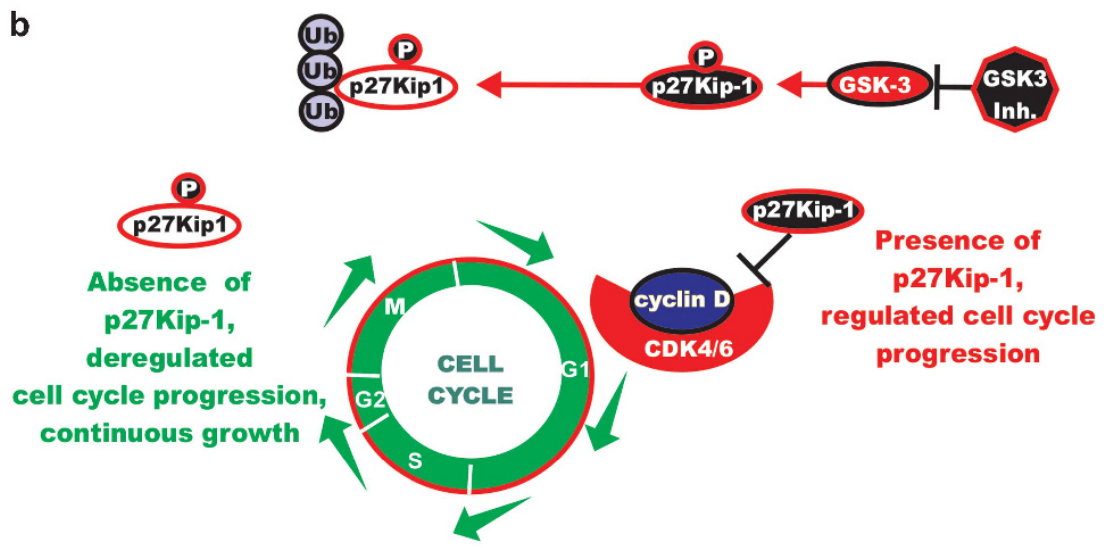

C
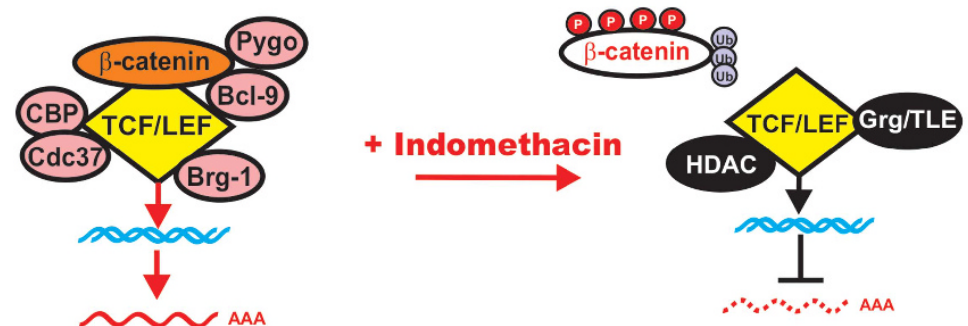

d

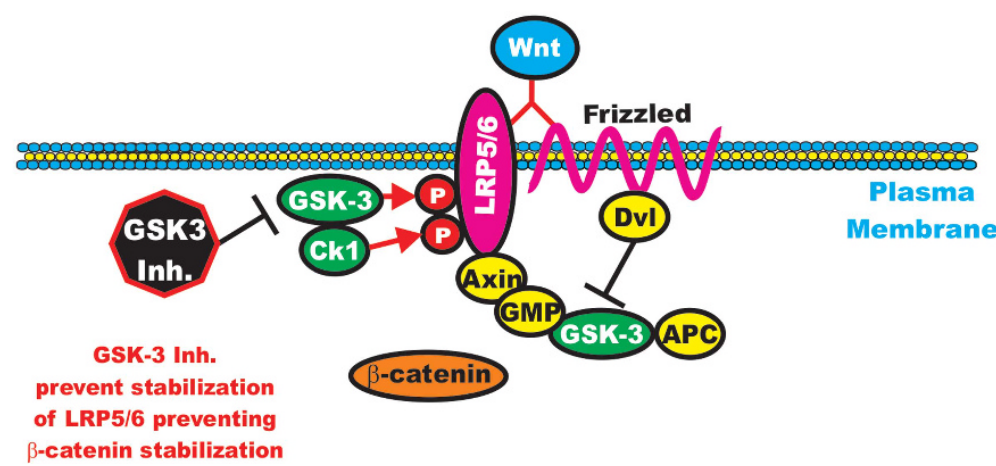

Figure 7. Effects of targeting GSK-3 in leukemia. Targeting of GSK-3 can interrupt important points in leukemogenesis. (a) Targeting GSK-3 may inhibit the activity of critical transcription factors such as CREB that are important in LICs. (b) Targeting GSK-3 may inhibit suppression of p2 $7^{\mathrm{Kip}-1}$, and thus cell cycle arrest will occur. Open p $27^{\mathrm{Kip}-1}$ means degraded protein. (c) It may also be important in certain instances to target $\beta$-catenin with drugs such as indomethacin as $\beta$-catenin levels will increase when GSK-3 is inhibited. (d) Inhibiting GSK-3 prevents the phosphorylation of LRP5/6 that prevents $\beta$-catenin stabilization. This figure is provided to elicit the possibility of targeting GSK-3 in leukemia.

hydrophobicity problems with the current IWP2 compound; however, attempts are being made to modify the IWP2 compound or to isolate related compounds that have better solubility. As Wnt signals are critical for LICs, variations of the IWP2 compound may become important in leukemia therapy. A comprehensive list of Wnt pathway inhibitors, their modes of actions and the cancer models they have been examined is presented in the review by Anastas and Moon. ${ }^{68}$

\section{SUMMARY}

GSK- $3 \alpha$ and $\beta$ are critical enzymes involved in the regulation of many biological processes. In this review, we have focused more 
on the effects that GSK-3 has on cancer, but it also has critical roles in many other physiological processes. Although GSK-3 is a downstream target of Akt, it can also interact with TSC2 to regulate mTORC1. GSK-3 can also interact with mTORC1 to regulate p70S6K that can indirectly regulate Akt. Thus, GSK-3 has intricate roles in the regulation of signaling pathways. GSK-3 also serves to regulate the $\mathrm{Wnt} / \beta$-catenin pathway at multiple levels; in some cases, it inhibits the activity of Wnt/ $\beta$-catenin pathway, whereas in other cases it promotes the pathway. This latter effect is especially prominent in LSCs, where GSK-3 inhibitors may prove clinically effective; however, they probably will have to be administered with $\beta$-catenin or downstream TCF/LEF inhibitors. GSK-3 also interacts with the Hh, Notch, Raf/MEK/ERK and other important regulatory pathways. It is interesting to consider that inhibiting GSK-3 does not have more dire consequences as so many pathways will be affected. However, many patients have been treated with the GSK-3 inhibitor lithium for years without apparent increases in the cancer incidence. Clearly, GSK-3 is a kinase with many biochemical effects. Further understanding of these effects may result in appropriate therapies for certain leukemias.

\section{CONFLICT OF INTEREST}

The authors declare no conflict of interest.

\section{ACKNOWLEDGEMENTS}

FEB was supported in part by the Triad Chapter of Golfers Against Cancer (2013) $M C$ and GM were supported in part by grants from the Italian MIUR FIRB-MERIT (RBNE08YYBM). MC was also supported in part by a grant to the CNR from the Italian Ministry of Economy and Finance for the Project FaReBio di Qualità. LC was supported in part by MIUR-PRIN 2009 and Italian MIUR-FIRB Accordi di Programma 2010. ABD was supported in part by grants from the USAMRMC BC022276, the Intramural RECDA Award and the Italian Association for Cancer Research (AIRC). ML was supported in part by a grant from the Italian Ministry of Health, Ricerca Finalizzata Stemness 2008 entitled 'Molecular Determinants of Stemness and Mesenchymal Phenotype in Breast Cancer'. AMM was supported in part by grants from MIUR FIRB 2010 (RBAP10447J-003) and 2011 (RBAP11ZJFA_001). RM was supported in part by grants from CRO, the Italian Association for Cancer Research (AIRC; RM PI grant and MCO10016), the Italian Ministry of Health and Regione Friuli Venezia-Giulia.

\section{REFERENCES}

1 Embi N, Rylatt DB, Cohen P. Glycogen synthase kinase-3 from rabbit skeletal muscle. Separation from cyclic-AMP-dependent protein kinase and phosphorylase kinase. Eur J Biochem 1980; 107: 519-527.

2 Woodgett JR. Molecular cloning and expression of glycogen synthase kinase-3/factor A. EMBO J 1990; 9: 2431-2438.

3 Gao C, Holscher C, Liu Y, Li L. GSK3: a key target for the development of novel treatments for type 2 diabetes mellitus and Alzheimer disease. Rev Neurosci 2012; 23: 1-11.

4 Juhaszova M, Zorov DB, Yaniv Y, Nuss HB, Wang S, Sollott SJ. Role of glycogen synthase kinase-3[beta] in cardioprotection. Circ Res 2009; 104: 1240-1252.

5 Shimura T. Acquired radioresistance of cancer and the AKT/GSK3beta/cyclin D1 overexpression cycle. J Radiat Res 2011; 52: 539-544.

6 Fu Y, Hu D, Qiu J, Xie X, Ye F, Lu WG. Overexpression of glycogen synthase kinase-3 in ovarian carcinoma cells with acquired paclitaxel resistance Int J Gynecol Cancer 2011; 21: 439-444.

7 Kawazoe H, Bilim VN, Ugolkov AV, Yuuki K, Naito S, Nagaoka A et al. GSK-3 inhibition in vitro and in vivo enhances antitumor effect of sorafenib in renal cell carcinoma (RCC). Biochem Biophys Res Commun 2012; 423: 490-495.

8 Welham MJ, Kingham E, Sanchez-Ripoll Y, Kumpfmueller B, Storm M, Bone H. Controlling embryonic stem cell proliferation and pluripotency: the role of PI3K- and GSK-3-dependent signalling. Biochem Soc Trans 2011; 39: 674-678.

9 Gandillet A, Park S, Lassailly F, Griessinger E, Vargaftig J, Filby A et al. Heterogeneous sensitivity of human acute myeloid leukemia to catenin down-modulation. Leukemia 2011; 25: 770-780.

10 Van Coppernolle S, Vanhee S, Verstichel G, Snauwaert S, van der Spek A, Velghe I et al. Notch induces human T-cell receptor +thymocytes to differentiate along a parallel, highly proliferative and bipotent CD4 CD8 double-positive pathway. Leukemia 2012; 26: 127-138.

11 Wickremasinghe RG, Prentice AG, Steele AJ. p53 and Notch signaling in chronic lymphocytic leukemia: clues to identifying novel therapeutic strategies. Leukemia 2011; 25: 1400-1407.

12 Masiero M, Minuzzo S, Pusceddu I, Moserle L, Persano L, Agnusdei V et al. Notch3-mediated regulation of MKP-1 levels promotes survival of $T$ acute lymphoblastic leukemia cells. Leukemia 2011; 25: 588-598.

13 Schwarzer R, Dorken B, Jundt F. Notch is an essential upstream regulator of NF-kB and is relevant for survival of Hodgkin and Reed-Sternberg cells. Leukemia 2012; 26: 806-813.

14 Blackburn JS, Liu S, Raiser DM, Martinez SA, Feng H, Meeker ND et al. Notch signaling expands a pre-malignant pool of T-cell acute lymphoblastic leukemia clones without affecting leukemia-propagating cell frequency. Leukemia 2012; 26: $2069-2078$

15 Xu D, Hu J, Xu S, De Bruyne E, Menu E, Van Camp B et al. Dll1/Notch activation accelerates multiple myeloma disease development by promoting CD138+ MM-cell proliferation. Leukemia 2012; 26: 1402-1405.

16 Xu S, Evans H, Buckle C, De Veirman K, Hu J, Xu D et al. Impaired osteogenic differentiation of mesenchymal stem cells derived from multiple myeloma patients is associated with a blockade in the deactivation of the Notch signaling pathway. Leukemia 2012; 26: 2546-2549.

17 Shepherd C, Banerjee L, Cheung CW, Mansour MR, Jenkinson S, Gale RE et al. $\mathrm{PI} 3 \mathrm{~K} / \mathrm{mTOR}$ inhibition upregulates NOTCH-MYC signalling leading to an impaired cytotoxic response. Leukemia 2013; 27: 650-660.

18 Wang R, Xia L, Gabrilove J, Waxman S, Jing Y. Downregulation of Mcl-1 through GSK-3 activation contributes to arsenic trioxide-induced apoptosis in acute myeloid leukemia cells. Leukemia 2013; 27: 315-324.

19 Si J, Mueller L, Collins SJ. GSK3 inhibitors enhance retinoic acid receptor activity and induce the differentiation of retinoic acid-sensitive myeloid leukemia cells. Leukemia 2011; 25: 1914-1918.

20 Luis TC, Ichii $M$, Brugman MH, Kincade $P$, Staal FJ. Wht signaling strength regulates normal hematopoiesis and its deregulation is involved in leukemia development. Leukemia 2012; 26: 414-421.

21 Mar BG, Amakye D, Aifantis I, Buonamici S. The controversial role of the Hedgehog pathway in normal and malignant hematopoiesis. Leukemia 2011 25: $1665-1673$.

22 Pajcini KV, Speck NA, Pear WS. Notch signaling in mammalian hematopoietic stem cells. Leukemia 2011; 25: 1525-1532.

23 Patel S, Woodgett J. Glycogen synthase kinase-3 and cancer: good cop, bad cop? Cancer Cell 2008; 14: 351-353.

24 Doble BW, Woodgett JR. GSK-3: tricks of the trade for a multi-tasking kinase. J Cell Sci 2003; 116: 1175-1186.

25 Sutherland C. What are the bona fide GSK3 substrates? Int J Alzheimers Dis 2011; 2011: Article ID 505607; 23 pages.

26 Kockeritz L, Doble B, Patel S, Woodgett JR. Glycogen synthase kinase-3--an overview of an over-achieving protein kinase. Curr Drug Targets 2006 7: 1377-1388.

27 Cole A, Frame S, Cohen P. Further evidence that the tyrosine phosphorylation of glycogen synthase kinase-3 (GSK3) in mammalian cells is an autophosphorylation event. Biochem J 2004; 377: 249-255.

28 Bhat RV, Shanley J, Correll MP, Fieles WE, Keith RA, Scott CW et al. Regulation and localization of tyrosine 216 phosphorylation of glycogen synthase kinase-3beta in cellular and animal models of neuronal degeneration. Proc Natl Acad Sci USA 2000; 97: 11074-11079.

29 Bijur GN, Jope RS. Proapoptotic stimuli induce nuclear accumulation of glycogen synthase kinase-3 beta. J Biol Chem 2001; 276: 37436-37442.

30 Hartigan JA, Xiong WC, Johnson GV. Glycogen synthase kinase 3beta is tyrosine phosphorylated by PYK2. Biochem Biophys Res Commun 2001; 284: 485-489.

31 Lesort M, Jope RS, Johnson GV. Insulin transiently increases tau phosphorylation: involvement of glycogen synthase kinase-3beta and Fyn tyrosine kinase. J Neurochem 1999; 72: 576-584.

32 Thornton TM, Pedraza-Alva G, Deng B, Wood CD, Aronshtam A, Clements JL et al. Phosphorylation by p38 MAPK as an alternative pathway for GSK3beta inactivation. Science 2008; 320: 667-670.

33 Bennecib M, Gong CX, Grundke-lqbal I, Iqbal K. Role of protein phosphatase-2A and -1 in the regulation of GSK-3, cdk 5 and cdc2 and the phosphorylation of tau in rat forebrain. FEBS Lett 2000; 485: 87-93.

34 Shin S, Wolgamott L, Yu Y, Blenis J, Yoon SO. Glycogen synthase kinase (GSK)-3 promotes p70 ribosomal protein S6 kinase (p70S6K) activity and cell proliferation. Proc Natl Acad Sci USA 2011; 108: 1204-1213.

35 McQueen J, van Dyk D, Young B, Loewen C, Measday V. The Mck1 GSK-3 kinase inhibits the activity of Clb2-Cdk1 post-nuclear division. Cell Cycle 2012; 11: $3421-3432$ 
36 Wang Z, Smith KS, Murphy M, Piloto O, Somervaille TC, Cleary ML. Glycogen synthase kinase 3 in MLL leukaemia maintenance and targeted therapy. Nature 2008; 455: 1205-1209.

37 Rossig L, Badorff C, Holzmann Y, Zeiher AM, Dimmeler S. Glycogen synthase kinase-3 couples AKT-dependent signaling to the regulation of p21Cip1 degradation. J Biol Chem 2002; 277: 9684-9689.

38 Diehl JA, Cheng M, Roussel MF, Sherr CJ. Glycogen synthase kinase- 3beta regulates cyclin D1 proteolysis and subcellular localization. Genes Dev 1998; 12: 3499-3511.

39 Welcker M, Singer J, Loeb KR, Grim J, Bloecher A, Gurien-West M et al. Multisite phosphorylation by Cdk2 and GSK3 controls cyclin E degradation. Mol Cell 2003; 12: 381-392.

40 Mishra R. Glycogen synthase kinase 3 beta: can it be a target for oral cancer? Mol Cancer 2010; 9: 144.

41 Bianchi M, De Lucchini S, Marin O, Turner DL, Hanks SK, Villa-Moruzzi E. Regulation of FAK Ser-722 phosphorylation and kinase activity by GSK3 and PP1 during cell spreading and migration. Biochem J 2005; 391: 359-370.

42 Belkhiri A, Dar AA, Zaika A, Kelley M, El-Rifai W. t-Darpp promotes cancer cell survival by up-regulation of $\mathrm{BCl} 2$ through Akt-dependent mechanism. Cancer Res 2008; 68: 395-403.

43 Ding Q, He X, Hsu JM, Xia W, Chen CT, Li LY et al. Degradation of Mcl-1 by beta-TrCP mediates glycogen synthase kinase 3-induced tumor suppression and chemosensitization. Mol Cell Biol 2007; 27: 4006-4017.

44 Nifoussi SK, Vrana JA, Domina AM, De Biasio A, Gui J, Gregory MA et al. Thr 163 phosphorylation causes $\mathrm{Mcl}-1$ stabilization when degradation is independent of the adjacent GSK3-targeted phosphodegron, promoting drug resistance in cancer. PLoS One 2012; 7: e47060.

45 Zhao Y, Altman BJ, Coloff JL, Herman CE, Jacobs SR, Wieman HL et al. Glycogen synthase kinase 3alpha and 3beta mediate a glucose-sensitive antiapoptotic signaling pathway to stabilize Mcl-1. Mol Cell Biol 2007; 27: 4328-4339.

46 Zhou F, Zhang L, van Laar T, van Dam H, Ten Dijke P. GSK3beta inactivation induces apoptosis of leukemia cells by repressing the function of c-Myb. Mol Biol Cell 2011; 22: 3533-3540.

47 Ross SE, Erickson RL, Hemati N, MacDougald OA. Glycogen synthase kinase 3 is an insulin-regulated C/EBPalpha kinase. Mol Cell Biol 1999; 19: 8433-8441.

48 MacAulay K, Doble BW, Patel S, Hansotia T, Sinclair EM, Drucker DJ et al. Glycogen synthase kinase 3alpha-specific regulation of murine hepatic glycogen metabolism. Cell Metab 2007; 6: 329-337.

49 Kaidanovich-Beilin O, Lipina TV, Takao K, van Eede M, Hattori S, Laliberté C et al. Abnormalities in brain structure and behavior in GSK-3alpha mutant mice. Mol Brain 2009; 2: 35

50 Soutar MP, Kim WY, Williamson R, Peggie M, Hastie CJ, McLauchlan $\mathrm{H}$ et al. Evidence that glycogen synthase kinase-3 isoforms have distinct substrate preference in the brain. Neurochem 2010; 115: 974-983.

51 Banerji V, Frumm SM, Ross KN, Li LS, Schinzel AC, Hahn CK et al. The intersection of genetic and chemical genomic screens identifies GSK-3alpha as a target in human acute myeloid leukemia. J Clin Invest 2012; 122: 935-947.

52 Bolzoni M, Donofrio G, Storti P, Guasco D, Toscani D, Lazzaretti M et al. Myeloma cells inhibit non-canonical wnt co-receptor ror2 expression in human bone marrow osteoprogenitor cells: effect of wnt5a/ror2 pathway activation on the osteogenic differentiation impairment induced by myeloma cells. Leukemia 2013; 27: 451-463.

53 Morgan RG, Pearn L, Liddiard K, Pumford SL, Burnett AK, Tonks A et al. $\beta$-Catenin is overexpressed in acute myeloid leukemia and promotes the stabilization and nuclear localization of catenin. Leukemia 2013; 27: 336-343.

54 Liu P, Xu B, Shen W, Zhu H, Wu W, Fu Y, Chen $\mathrm{H}$ et al. Dysregulation of TNF-induced necroptotic signaling in chronic lymphocytic leukemia: suppression of CYLD gene by LEF1. Leukemia 2012; 26: 1293-1300.

55 Stengel C, Cheung CW, Quinn J, Yong K, Khwaja A. Optimal induction of myeloma cell death requires dual blockade of phosphoinositide 3-kinase and mTOR signalling and is determined by translocation subtype. Leukemia 2012; 26: $1761-1770$.

56 Willems L, Chapuis N, Puissant A, Maciel T, Green AS, Jacque N et al. The dual mTORC1 and mTORC2 inhibitor AZD8055 has anti-tumor activity in acute myeloid leukemia. Leukemia 2012; 26: 1195-1202.

57 Rao E, Jiang C, Ji M, Huang X, lqbal J, Lenz G, Wright G et al. The miRNA-17 92 cluster mediates chemoresistance and enhances tumor growth in mantle cell lymphoma via PI3K/AKT pathway activation. Leukemia 2012; 26: 1064-1072.

58 Fuka G, Kantner HP, Grausenburger R, Inthal A, Bauer E, Krapf G et al. Silencing of ETV6/RUNX1 abrogates PI3K/AKT/mTOR signaling and impairs reconstitution of leukemia in xenografts. Leukemia 2012; 26: 927-933.

59 Fruchon S, Kheirallah S, Al Saati T, Ysebaert L, Laurent C, Leseux L, Fournie JJ et al. Involvement of the Syk-mTOR pathway in follicular lymphoma cell invasion and angiogenesis. Leukemia 2012; 26: 795-805.
60 Ramakrishnan V, Ansell S, Haug J, Grote D, Kimlinger T, Stenson M et al. MRK003, a -secretase inhibitor exhibits promising in vitro pre-clinical activity in multiple myeloma and non-Hodgkin's lymphoma. Leukemia 2012; 26: 340-348.

61 Simioni C, Neri LM, Tabellini G, Ricci F, Bressanin D, Chiarini F et al. Cytotoxic activity of the novel Akt inhibitor, MK-2206, in T-cell acute lymphoblastic leukemia. Leukemia 2012; 26: 2336-2342.

62 Sykes SM, Lane SW, Bullinger L, Kalaitzidis D, Yusuf R, Saez B et al. AKT/FOXO signaling enforces reversible differentiation blockade in myeloid leukemias. Cell 2011; 146: 697-708.

63 Grimaldi C, Chiarini F, Tabellini G, Ricci F, Tazzari PL, Battistelli M et al. AMP-dependent kinase/mammalian target of rapamycin complex 1 signaling in T-cell acute lymphoblastic leukemia: therapeutic implications. Leukemia 2012; 26: 91-100.

64 Martelli AM, Evangelisti C, Chappell W, Abrams SL, Bäsecke J, Stivala F et al. Targeting the translational apparatus to improve leukemia therapy: roles of the PI3K/PTEN/Akt/mTOR pathway. Leukemia 2011; 25: 1064-1079.

65 Wang H, Brown J, Gu Z, Garcia CA, Liang R, Alard P et al. Convergence of the mammalian target of rapamycin complex 1- and glycogen synthase kinase 3 - $\beta$-signaling pathways regulates the innate inflammatory response. J Immunol 2011; 186: 5217-5226.

66 Inoki K, Ouyang H, Zhu T, Lindvall C, Wang Y, Zhang X et al. TSC2 integrates Wnt and energy signals via a coordinated phosphorylation by AMPK and GSK3 to regulate cell growth. Cell 2006; 126: 955-968.

67 Clevers H, Nusse R. Wnt/ $\beta$-catenin signaling and disease. Cell 2012; 149: 1192-1205.

68 Anastas JN, Moon RT. WNT signalling pathways as therapeutic targets in cancer. Nat Rev Cancer 2013; 13: 11-26.

69 Ikeda S, Kishida S, Yamamoto H, Murai H, Koyama S, Kikuchi A. Axin, a negative regulator of the Wnt signaling pathway, forms a complex with GSK-3beta and beta-catenin and promotes GSK-3beta-dependent phosphorylation of beta-catenin. EMBO J 1998; 17: 1371-1384.

70 Schwarz-Romond T, Asbrand C, Bakkers J, Kuhl M, Schaeffer HJ, Huelsken J et al. The ankyrin repeat protein diversin recruits casein kinase I epsilon to the $\beta$-catenin degradation complex and acts in both canonical Wnt and Wnt/JNK signaling. Genes Dev 2002; 16: 2073-2084.

71 Ferkey DM, Kimelman D. Glycogen synthase kinase-3 beta mutagenesis identifies a common binding domain for GBP and Axin. J Biol Chem 2002; 277: 16147-16152.

72 Franca-Koh J, Yeo M, Fraser E, Young N, Dale TC. The regulation of glycogen synthase kinase-3 nuclear export by Frat/GBP. J Biol Chem 2002; 277: 43844-43848

73 Ding VW, Chen RH, McCormick F. Differential regulation of glycogen synthase kinase 3beta by insulin and Wnt signaling. J Biol Chem 2000; 275: 32475-32481.

74 Yuan H, Mao J, Li L, Wu D. Suppression of glycogen synthase kinase activity is not sufficient for leukemia enhancer factor-1 activation. J Biol Chem 1999; 274: 30419-30423.

75 Zeng $\mathrm{X}$, Tamai $\mathrm{K}$, Doble $\mathrm{B}$, Li S, Huang $\mathrm{H}$, Habas $\mathrm{R}$ et al. A dual-kinase mechanism for Wnt co-receptor phosphorylation and activation. Nature 2005; 438: 873-877.

76 Davidson G, Wu W, Shen J, Bilic J, Fenger U, Stannek P et al. Casein kinase 1 gamma couples Wnt receptor activation to cytoplasmic signal transduction. Nature 2005; 438: 867-872.

77 Major MB, Camp ND, Berndt JD, Yi X, Goldenberg SJ, Hubbert C et al. Wilms tumor suppressor WTX negatively regulates WNT/beta-catenin signaling. Science 2007; 316: 1043-1046.

78 Valvezan AJ, Zhang F, Diehl JA, Klein PS. Adenomatous polyposis coli (APC) regulates multiple signaling pathways by enhancing glycogen synthase kinase-3 (GSK-3) activity. J Biol Chem 2012; 287: 3823-3832.

79 Lustig B, Jerchow B, Sachs M, Weiler S, Pietsch T, Karsten U et al. Negative feedback loop of Wnt signaling through upregulation of conductin/axin2 in colorectal and liver tumors. Mol Cell Biol 2002; 22: 1184-1193.

80 Niida A, Hiroko T, Kasai M, Furukawa $Y$, Nakamura $Y$, Suzuki $Y$ et al. DKK1, a negative regulator of Wnt signaling, is a target of the beta-catenin/TCF pathway. Oncogene 2004; 23: 8520-8526.

81 Yoshioka S, King ML, Ran S, Okuda H, MacLean 2nd JA, McAsey ME et al. WNT7A regulates tumor growth and progression in ovarian cancer through the WNT/B-catenin pathway. Mol Cancer Res 2012; 10: 469-482.

82 Ochoa-Hernández AB, Ramos-Solano M, Meza-Canales ID, García-Castro B, Rosales-Reynoso MA, Rosales-Aviña JA et al. Peripheral T-lymphocytes express WNT7A and its restoration in leukemia-derived lymphoblasts inhibits cell proliferation. BMC Cancer 2012; 12: 60

83 Bitler BG, Nicodemus JP, Li H, Cai Q, Wu H, Hua X et al. Wnt5a suppresses epithelial ovarian cancer by promoting cellular senescence. Cancer Res 2011; 71: 6184-6194. 
84 Kremenevskaja N, von Wasielewski R, Rao AS, Schöfl C, Andersson T, Brabant G. Wnt-5a has tumor suppressor activity in thyroid carcinoma. Oncogene 2005; 24: 2144-2154.

85 Liang H, Chen Q, Coles AH, Anderson SJ, Pihan G, Bradley A et al. Wnt5a inhibits $B$ cell proliferation and functions as a tumor suppressor in hematopoietic tissue. Cancer Cell 2003; 4: 349-360.

$86 \mathrm{Wu}$ QL, Zierold C, Ranheim EA. Dysregulation of Frizzled 6 is a critical component of B-cell leukemogenesis in a mouse model of chronic lymphocytic leukemia. Blood 2009; 113: 3031-3039.

87 Yeung J, Esposito MT, Gandillet A, Zeisig BB, Griessinger E, Bonnet D et al. $\beta$-catenin mediates the establishment and drug resistance of MLL leukemic stem cells. Cancer Cell 2010; 18: 606-618.

88 Jamieson CH, Ailles LE, Dylla SJ, Muijtjens M, Jones C, Zehnder JL et al. Granulocyte-macrophage progenitors as candidate leukemic stem cells in blast-crisis CML. N Engl J Med 2004; 351: 657-667.

89 Willert K, Brown JD, Danenberg E, Duncan AW, Weissman IL, Reya T et al. Wnt proteins are lipid-modified and can act as stem cell growth factors. Nature 2003; 423: 448-452.

90 Duncan AW, Rattis FM, DiMascio LN, Congdon KL, Pazianos G, Zhao C et al. Integration of Notch and Wnt signaling in hematopoietic stem cell maintenance. Nat Immunol 2005; 6: 314-322.

91 Reya T, Duncan AW, Ailles L, Domen J, Scherer DC, Willert K et al. A role for Wnt signalling in self-renewal of haematopoietic stem cells. Nature 2003; 423: 409-414.

92 ten Berge D, Kurek D, Blauwkamp T, Koole W, Maas A, Eroglu E et al. Embryonic stem cells require Wnt proteins to prevent differentiation to epiblast stem cells. Nat Cell Biol 2011; 13: 1070-1075.

93 Huang J, Zhang Y, Bersenev A, O'Brien WT, Tong W, Emerson SG et al. Pivotal role for glycogen synthase kinase-3 in hematopoietic stem cell homeostasis in mice. J Clin Invest 2009; 119: 3519-3529.

94 Yilmaz OH, Valdez R, Theisen BK, Guo W, Ferguson DO, Wu H et al. Pten dependence distinguishes haematopoietic stem cells from leukaemia-initiating cells. Nature 2006; 441: 475-482.

95 Chen C, Liu Y, Liu R, Ikenoue T, Guan KL, Liu Y et al. TSC-mTOR maintains quiescence and function of hematopoietic stem cells by repressing mitochondrial biogenesis and reactive oxygen species. J Exp Med 2008; 205: 2397-2408.

96 Lee JY, Nakada D, Yilmaz OH, Tothova Z, Joseph NM, Lim MS et al. mTOR activation induces tumor suppressors that inhibit leukemogenesis and deplete hematopoietic stem cells after Pten deletion. Cell Stem Cell 2010; 7: 593-605.

97 Huang J, Zhang Y, Bersenev A, O'Brien WT, Tong W, Emerson SG et al. Pivotal role for glycogen synthase kinase-3 hematopoietic stem cell homeostasis in mice. J Clin Invest 2009; 119: 3519-3529.

98 Gurumurthy S, Xie SZ, Alagesan B, Kim J, Yusuf RZ, Saez B et al. The Lkb1 metabolic sensor maintains haematopoietic stem cell survival. Nature 2010; 468: 659-663.

99 Huang J, Nguyen-McCarty M, Hexner EO, Danet-Desnoyers G, Klein PS. Maintenance of hematopoietic stem cells through regulation of Wnt and mTOR pathways. Nat Med 2012; 18: 1778-1785.

100 Ito K, Carracedo A, Weiss D, Arai F, Ala U, Avigan DE et al. A PML-PPAR-delta pathway for fatty acid oxidation regulates hematopoietic stem cell maintenance. Nat Med 2012; 18: 1350-1358.

101 Ito K, Bernardi R, Morotti A, Matsuoka S, Saglio G, Ikeda Y et al. PML targeting eradicates quiescent leukaemia-initiating cells. Nature 2008; 453 1072-1078.

102 Sato N, Meijer L, Skaltsounis L, Greengard P, Brivanlou AH. Maintenance of pluripotency in human and mouse embryonic stem cells through activation of Wnt signaling by a pharmacological GSK-3-specific inhibitor. Nat Med 2004; 10: $55-63$.

103 Doble BW, Patel S, Wood GA, Kockeritz LK, Woodgett JR. Functional redundancy of GSK-3alpha and GSK-3beta in Wnt/beta-catenin signaling shown by using an allelic series of embryonic stem cell lines. Dev Cell 2007; 12: 957-971.

104 Jeannet G, Scheller M, Scarpellino L, Duboux S, Gardiol N, Back J et al. Long-term, multilineage hematopoiesis occurs in the combined absence of beta-catenin and gamma-catenin. Blood 2008; 111: 142-149.

105 Majeti R, Becker MW, Tian Q, Lee TL, Yan X, Liu R et al. Dysregulated gene expression networks in human acute myelogenous leukemia stem cells. Proc Natl Acad Sci USA 2009; 106: 3396-3401.

106 Stein RS, Vogler WR, Lefante J. Failure of lithium to limit neutropenia significantly during induction therapy of acute myelogenous leukemia. A Southeastern Cancer Study Group study. Am J Clin Oncol 1984; 7: 365-369.

107 Gupta K, Gulen F, Sun L, Aguilera R, Chakrabarti A, Kiselar J et al. GSK3 is a regulator of RAR-mediated differentiation. Leukemia 2012; 26: 1277-1285.
108 Heidel FH, Bullinger L, Feng Z, Zu W, Neff TA, Stein L et al. Genetic and pharmacologic inhibition of beta-catenin targets imatinib-resistant leukemia stem cells in CML. Cell Stem Cell 2012; 10: 412-424.

109 Zhao C, Blum J, Chen A, Kwon HY, Jung SH, Cook JM et al. Loss of beta-catenin impairs the renewal of normal and CML stem cells in vivo. Cancer Cell 2007; 12: $528-541$.

110 Li L, Wang L, Li L, Wang Z, Ho Y, McDonald T et al. Activation of p53 by SIRT1 inhibition enhances elimination of CML leukemia stem cells in combination with imatinib. Cancer Cell 2012; 21: 266-281.

111 Holloway KR, Calhoun TN, Saxena M, Metoyer CF, Kandler EF, Rivera CA et al. SIRT1 regulates dishevelled proteins and promotes transient and constitutive Wnt signaling. Proc Natl Acad Sci USA 2010; 107: 9216-9221.

112 Gu Y, Chen T, Meng Z, Gan Y, Xu X, Lou G et al. CaMKIlgamma, a critical regulator of CML stem/progenitor cells, is a target of the natural product berbamine. Blood 2012; 120: 4829-4839.

113 Abrahamsson AE, Geron I, Gotlib J, Dao KH, Barroga CF, Newton IG et al. Glycogen synthase kinase 3beta missplicing contributes to leukemia stem cell generation. Proc Natl Acad Sci USA 2009; 106: 3925-3929.

114 MacNicol MC, Cragle CE, MacNicol AM. Context-dependent regulation of Musashi-mediated mRNA translation and cell cycle regulation. Cell Cycle 2011; 10: 39-44.

115 Kanwar SS, Yu Y, Nautiyal J, Patel BB, Majumdar AP. The Wnt/beta-catenin pathway regulates growth and maintenance of colonospheres. Mol Cancer 2010; 9: 212.

116 Ito T, Kwon HY, Zimdahl B, Congdon KL, Blum J, Lento WE et al. Regulation of myeloid leukaemia by the cell-fate determinant Musashi. Nature 2010; 466: 765-768.

117 Espinosa L, Inglés-Esteve J, Aguilera C, Bigas A. Phosphorylation by glycogen synthase kinase-3 beta down-regulates Notch activity, a link for Notch and Wn pathways. J Biol Chem 2003; 278: 32227-32235.

118 Colaluca IN, Tosoni D, Nuciforo P, Senic-Matuglia F, Galimberti V, Viale $\mathrm{G}$ et al. NUMB controls p53 tumour suppressor activity. Nature 2008; 451 : 76-80.

119 Pece S, Confalonieri S, Romano PR, Di Fiore PP. NUMB-ing down cancer by more than just a NOTCH. Biochim Biophys Acta 2011; 1815: 26-43.

120 Fereshteh M, Ito T, Kovacs JJ, Zhao C, Kwon HY, Tornini V et al. $\beta$-Arrestin2 mediates the initiation and progression of myeloid leukemia. Proc Natl Acad Sci USA 2012; 109: 12532-12537.

121 Chen W, ten Berge D, Brown J, Ahn S, Hu LA, Miller WE et al. Dishevelled 2 recruits beta-arrestin 2 to mediate Wnt5A-stimulated endocytosis of Frizzled 4. Science 2003; 301: 1391-1394.

122 O'Brien WT, Huang J, Buccafusca R, Garskof J, Valvezan AJ, Berry GT et al. Glycogen synthase kinase- 3 is essential for $\beta$-arrestin- 2 complex formation and lithium-sensitive behaviors in mice. J Clin Invest 2011; 121: 3756-3762.

123 Chalecka-Franaszek E, Chuang DM. Lithium activates the serine/threonine kinase Akt-1 and suppresses glutamate-induced inhibition of Akt-1 activity in neurons. Proc Natl Acad Sci USA 1999; 96: 8745-8750.

124 Yamamoto K, Nakamura Y, Saito K, Furusawa S. Expression of the NUP98/HOXA9 fusion transcript in the blast crisis of Philadelphia chromosome-positive chronic myelogenous leukaemia with $\mathrm{t}(7 ; 11)(\mathrm{p} 15 ; \mathrm{p} 15)$. Br J Haematol 2000; 109: 423-426.

125 Wang Y, Krivtsov AV, Sinha AU, North TE, Goessling W, Feng Z et al. The Wnt/ beta-catenin pathway is required for the development of leukemia stem cells in AML. Science 2010; 327: 1650-1653.

126 Castellone MD, Teramoto H, Williams BO, Druey KM, Gutkind JS. Prostaglandin E2 promotes colon cancer cell growth through a Gs-axin-beta-catenin signaling axis. Science 2005; 310: 1504-1510.

127 Coluccia AM, Vacca A, Duñach M, Mologni L, Redaelli S, Bustos VH et al. Bcr-Abl stabilizes beta-catenin in chronic myeloid leukemia through its tyrosine phosphorylation. EMBO J 2007; 26: 1456-1466.

128 Reddiconto G, Toto C, Palamà I, De Leo S, de Luca E, De Matteis S et al. Targeting of GSK-3 $\beta$ promotes imatinib-mediated apoptosis in quiescent CD34 + chronic myeloid leukemia progenitors, preserving normal stem cells. Blood 2012; 119: $2335-2345$.

129 Ougolkov AV, Bone ND, Fernandez-Zapico ME, Kay NE, Billadeau DD. Inhibition of glycogen synthase kinase-3 activity leads to epigenetic silencing of nuclear factor kappaB target genes and induction of apoptosis in chronic lymphocytic leukemia B cells. Blood 2007; 110: 735-742.

130 Piazza F, Manni S, Tubi LQ, Montini B, Pavan L, Colpo A et al. Glycogen synthase kinase-3 regulates multiple myeloma cell growth and bortezomib-induced cell death. BMC Cancer 2010; 10: 526.

131 Ikegame A, Ozaki S, Tsuji D, Harada T, Fujii S, Nakamura S et al. Small molecule antibody targeting HLA class I inhibits myeloma cancer stem cells by repressing pluripotency-associated transcription factors. Leukemia 2012; 26: 2124-2134. 
132 G-Amlak M, Uddin S, Mahmud D, Damacela I, Lavelle D, Ahmed M et al. Regulation of myeloma cell growth through Akt/Gsk3/forkhead signaling pathway. Biochem Biophys Res Commun 2002; 297: 760-764.

133 Rocques N, Abou Zeid N, Sii-Felice K, Lecoin L, Felder-Schmittbuhl MP, Eychène A et al. GSK-3-mediated phosphorylation enhances Maf-transforming activity. Mol Cell 2007; 28: 584-597.

134 Gunn WG, Krause U, Lee N, Gregory CA. Pharmaceutical inhibition of glycogen synthetase kinase-3beta reduces multiple myeloma-induced bone disease in a novel murine plasmacytoma xenograft model. Blood 2011; 117: 1641-1651.

135 Busino L, Millman SE, Scotto L, Kyratsous CA, Basrur V, O'Connor O et al. Fbxw7alpha and GSK3-mediated degradation of p100 is a pro-survival mechanism in multiple myeloma. Nat Cell Biol 2012; 14: 375-385.

136 Ricci P, Bandini G, Franchi P, Motta MR, Visani G, Calamandrei G. Haematological effects of lithium carbonate: a study in 56 psychiatric patients. Haematologica 1981; 66: 627-633.

137 Ballin A, Lehman D, Sirota P, Litvinjuk U, Meytes D. Increased number of peripheral blood CD34 + cells in lithium-treated patients. Br J Haematol 1998; 100: 219-221.

138 Hedgepeth CM, Conrad L, Zhang J, Huang HC, Lee VM, Klein PS. Activation of the Wnt signaling pathway: a molecular mechanism for lithium action. Dev Biol 1997; 185: 82-91.

139 Ougolkov AV, Billadeau DD. Inhibition of glycogen synthase kinase-3. Methods Mol Biol 2008; 468: 67-75.

140 Mirlashari MR, Randen I, Kjeldsen-Kragh J. Glycogen synthase kinase-3 (GSK-3) inhibition induces apoptosis in leukemic cells through mitochondria-dependent pathway. Leuk Res 2012; 36: 499-508.

141 Huang HS, Liu ZM, Cheng YL. Involvement of glycogen synthase kinase-3 $\beta$ in arsenic trioxide-induced p21 expression. Toxicol Sci 2011; 121: 101-109.

142 Alao JP, Stavropoulou AV, Lam EW, Coombes RC. Role of glycogen synthase kinase 3 beta (GSK3beta) in mediating the cytotoxic effects of the histone deacetylase inhibitor trichostatin A (TSA) in MCF-7 breast cancer cells. Mol Cancer 2006; 5: 40.

143 Bakre MM, Hoi A, Mong JC, Koh YY, Wong KY, Stanton LW. Generation of multipotential mesendodermal progenitors from mouse embryonic stem cells via sustained Wnt pathway activation. J Biol Chem 2007; 282: 31703-31712.

144 Riobo NA, Lu K, Ai X, Haines GM, Emerson Jr. CP. Phosphoinositide 3-kinase and Akt are essential for Sonic hedgehog signaling. Proc Natl Acad Sci USA 2006; 103: $4505-4510$
145 Bone HK, Damiano T, Bartlett S, Perry A, Letchford J, Sanchez Ripoli Y et al. Involvement of GSK-3 in regulation of murine embryonic stem cell self-renewal revealed by a series of bisindolylmaleimides. Chem Biol 2009; 16: 15-27.

146 Steelman LS, Franklin RA, Abrams SL, Chappell W, Kempf CR, Bäsecke J et al. Roles of the Ras/Raf/MEK/ERK pathway in leukemia therapy. Leukemia 2011; 25: $1080-1094$.

147 Silva A, Girio A, Cebola I, Santos Cl, Antunes F, Barata JT. Intracellular reactive oxygen species are essential for PI3K/Akt/mTOR-dependent IL-7-mediated viability of T-cell acute lymphoblastic leukemia cells. Leukemia 2011; 25: $960-967$.

148 Asano J, Nakano A, Oda A, Amou H, Hiasa M, Takeuchi K et al. The serine/threonine kinase Pim-2 is a novel anti-apoptotic mediator in myeloma cells. Leukemia 2011; 25: 1182-1188.

149 Evangelisti C, Ricci F, Tazzari P, Tabellini G, Battistelli M, Falcieri E et al. Targeted inhibition of mTORC1 and mTORC2 by active-site mTOR inhibitors has cytotoxic effects in T-cell acute lymphoblastic leukemia. Leukemia 2011; 25: 781-791.

150 Chen B, Dodge ME, Tang W, Lu J, Ma Z, Fan CW et al. Small molecule-mediated disruption of Wnt-dependent signaling in tissue regeneration and cancer. Nat Chem Biol 2009; 5: 100-107.

151 Song S, Christova T, Perusini S, Alizadeh S, Bao RY, Miller BW et al. Wnt inhibitor screen reveals iron dependence of beta-catenin signaling in cancers. Cancer Res 2011; 71: 7628-7639.

152 Kovacevic Z, Kalinowski DS, Lovejoy DB, Yu Y, Suryo Rahmanto Y, Sharpe PC et al. The medicinal chemistry of novel iron chelators for the treatment of cancer. Curr Top Med Chem 2011; 11: 483-499.

153 Tuynman JB, Vermeulen L, Boon EM, Kemper K, Zwinderman AH, Peppelenbosch MP et al. Cyclooxygenase-2 inhibition inhibits c-Met kinase activity and Wnt activity in colon cancer. Cancer Res 2008; 68: 1213-1220.

154 Huang SM, Mishina YM, Liu S, Cheung A, Stegmeier F, Michaud GA et al. Tankyrase inhibition stabilizes axin and antagonizes Wnt signalling. Nature 2009; 461: 614-620.

155 Tanaka K, Okabayashi K, Asashima M, Perrimon N, Kadowaki T. The evolutionarily conserved porcupine gene family is involved in the processing of the Wnt family. Eur J Biochem 2000; 267: 4300-4311.

This work is licensed under a Creative Commons AttributionNonCommercial-NoDerivs 3.0 Unported License. To view a copy of this license, visit http://creativecommons.org/licenses/by-nc-nd/3.0/ 